\title{
DFT Studies of Fluid-Minerals Interactions at the Molecular Level: Examples and Perspectives
}

\author{
H. Toulhoat ${ }^{1}$, M. Digne ${ }^{1}$, C. Arrouvel ${ }^{1}$ and P. Raybaud ${ }^{1}$ \\ 1 Institut français du pétrole, 1 et 4, avenue de Bois-Préau, 92852 Rueil-Malmaison Cedex - France \\ e-mail: herve.toulhoat@ifp.fr - mathieu.digne@ifp.fr - pascal.raybaud@ifp.fr
}

\begin{abstract}
Résumé - Études DFT des interactions fluides-minéraux à l'échelle moléculaire : exemples et perspectives - Le champ d'applications des méthodes de chimie théorique basées sur les «premiers principes » s'est considérablement accru ces dernières années, du fait de la combinaison de méthodes et d'algorithmes améliorés pour la résolution de l'équation de Schrödinger polyélectronique et de la croissance exponentielle de la puissance de calcul accessible à coût constant («loi de Moore »). En particulier, des études atomistiques des interfaces solide-fluide produisent à présent de manière quasi routinière de nouveaux résultats fondamentaux qualitatifs et quantitatifs concernant l'adsorption, la spéciation de surface en fonction des potentiels chimiques imposés, et la réactivité des espèces de surface. Une telle approche est à présent largement exploitée dans les domaines de la catalyse hétérogène et de la physique des surfaces, et dans une moindre mesure à ce jour en géochimie, bien que la situation évolue rapidement. De nombreuses questions fondamentales relatives aux phénomènes d'interaction entre fluides et minéraux peuvent en effet être étudiées $a b$ initio grâce à des modèles tripériodiques atomistiques d'interfaces fluide-solide, incluant jusqu'à 200 voire 300 atomes non équivalents. Nous illustrons ces propos par des résultats obtenus récemment à l'IFP, dont certains sont d'une importance primordiale pour la fabrication de supports de catalyseurs industriels, et qui peuvent aussi présenter un intérêt en géochimie minérale dans le contexte de la séquestration des gaz acides dans les roches poreuses souterraines :

- le mouillage réactif de la boehmite $\mathrm{AlOOH}$, et la prédiction de sa morphologie d'équilibre ;

- les propriétés acido-basiques de surface d'une alumine de transition;

- l'hydroxylation et la sulfhydrilation des surfaces de l'anatase $\mathrm{TiO}_{2}$.

À travers ces exemples, les performances de la théorie de la fonctionnelle de la densité électronique (DFT), ainsi que celles d'un certain nombre de techniques et stratégies de modélisation actuelles sont discutées.
\end{abstract}

\footnotetext{
Abstract - DFT Studies of Fluid-Minerals Interactions at the Molecular Level: Examples and Perspectives - The scope of applications of first-principle theoretical chemistry methods has been vastly expanded over the past years due to the combination of improved methods and algorithms for solving the polyelectronic Schrödinger equation with exponential growth of computer power available at constant cost (the so-called "Moore law"). In particular, atomistic studies of solid-fluid interfaces are now routinely producing new qualitative and quantitative insights into adsorption, surface speciation as a function of the prevailing chemical potentials, and reactivity of surface species. This approach is
} 
currently widely exploited in the fields of heterogeneous catalysis and surface physics, and so far to a lesser extent for geochemical purposes, although the situation is rapidly evolving. Many fundamental issues of fluid-minerals interaction phenomena can indeed be addressed ab initio with atomistic $3 D$ periodic models of fluid-solid interfaces involving up to 200-300 unequivalent atoms. We illustrate this proposal with recent IFP results, some of which are of primary interest with respect to the manufacture of catalysts supports, but which also show some relevance for inorganic geochemical issues in the context of the sequestration of acid gases in subsurface porous rocks:

- reactive wetting of boehmite $\mathrm{AlOOH}$ and morphology prediction;

- acido-basic surface properties of a transition alumina;

- hydroxylation and sulfhydrylation of anatase $\mathrm{TiO}_{2}$ surfaces.

Through these examples, the performances of DFT and a variety of up-to-date modeling techniques and strategies are discussed.

\section{INTRODUCTION}

In the past twenty years, the methods and tools of theoretical chemistry and physical chemistry have evolved tremendously, to the extent that nowadays there is no sub-discipline of chemistry or materials science that is outside the range of their application. Geochemistry is being concerned as well, both organic (application of diamondoids to investigation of petroleum thermal maturity, [1], molecular modeling of asphaltenes using structure elucidation programs in conjunction with molecular simulation programs, [2]) and inorganic (ab initio molecular dynamics study of a monomolecular water layer on octahedral and tetrahedral kaolinite surfaces [3], first principles study of illite-smectite and implications for clay-mineral systems [4], the melting curve of iron at the pressures of the earth's core from ab initio calculations [5]).

It is the purpose of this paper to show that even quite difficult problems associated with fluid/solid interfaces at extreme conditions are within reach of modern computational chemistry approaches like density functional theory (DFT). Such problems are raised when one considers the sequestration of large amounts of $\mathrm{CO}_{2}$, an acid gas, by injection into a brine saturated subsurface porous rock, like a depleted hydrocarbon reservoir or an aquifer. It is expected that some minerals will dissolve, other precipitate, whith crucial consequences on the porosity and permeability. Injectivity, but also long term stability of sealing rocks should be predictable on the basis of better appraised thermodynamics and kinetics of fluid-minerals reactions.

At this conference, J. Schott et al. have presented their work showing the crucial influence of detailed surface speciation, and of the description of the first and second coordination spheres of ions at water/mineral interfaces, in the rate laws governing either dissolution or precipitation of carbonate minerals [6]. Numerous other examples can be found within or beyond the inorganic geochemical literature, of the fruitfulness of a local and molecular description of interactions of fluids with minerals. In the present report, we try to illustrate the capabilities of DFT to that end.

\section{FUNDAMENTALS OF AB INITIO TECHNIQUES}

The breakthrough was achieved when Density Functional Theory [7] was rendered effective in variationaly solving the poly-electronic Schrödinger equation through the Kohn and Sham "one electron molecular orbital" using an effective potential strategy [8], combined with the Vosko, Wilk and Nusair [9] quantum Monte-Carlo study of the electron gas. This allowed parametrization of an efficient exchangecorrelation functional in the local density approximation (LDA). A "cheaper" electronic correlation energy became therefore available with DFT. Indeed, with a favourable prefactor, and a scaling behaviour of order $N^{2.5}$ to $N^{3}$ with respect to the number $N$ of basis functions, molecules of a respectable size became tractable $a b$ initio, or "from first principles" at the level of accuracy of post Hartree-Fock quantum chemical methods. The latter remain impeded by highly unfavourable scaling behaviours (e.g. $N^{4-5}$ for Moller Plesset perturbation methods, $N^{>7}$ for multi-determinantal configuration interaction methods).

Moreover, with the information technology era emerging in quasi synchronicity with DFT, and the in silico implementation of the "Moore law", ab initio theoretical chemistry was relatively rapidly able to escape the "ghetto" of diatomics of the first two rows of the periodic table, to venture into the real world. Relatively user-friendly and already highly efficient DFT codes, implementing geometry optimization, normal modes frequency calculations and transition states searches, such as Dmol [10], appeared in the early eighties on mainframe computers. Vectorial architectures were shown to be quite effective in linear algebra operations on large matrices and long vectors. Theses are typical of numerical theoretical chemistry algorithms in search of self-consistent variational solutions to the Schrödinger eigenvalue problem with wavefunctions represented by Slater determinants of molecular orbitals expanded over large basis sets of atomic orbitals. As the cost and speed of one million floating point operations (MegaFLOP or MFLOP) continued to decrease exponentially 
with time, and with the powerful graphical capability of workstations starting from the late eighties, modern molecular modeling was born. Rapidly increasing local random access memory (RAM) and disk space on workstations, together with the introduction of the reduced instruction set computer (RISC) architecture, allowed theoretical chemists to mass migrate their codes and heavy tasks from queues in mainframes to single-user local nodes, where they were happy to escape the jealous and suspicious competition of non-chemist computational scientists.

In the meantime, DFT, once its potential was demonstrated for molecular chemistry, (electrons interacting with a cluster of ionic cores in isolation in a vacuum and therefore represented by a wavefunction vanishing at infinite distance) started to pervade computational solid state physics. The perfect crystal is the starting point for a solid state physicist, hence he needs to represent electrons wandering in a coulombic potential which is periodic in the $X, Y$ and $Z$ axis of the primitive cell. He then notices that he has to add an extra dimension, the wave vector defined within the Brillouin zone, in order to describe the now periodic stationary electronic states. The discrete (quantized) set of molecular electronic eigenstates become bandstructures, and the energy of the HOMO (higher occupied molecular orbital) is now called the Fermi level. Moreover, since everything in the primitive box is repeating itself periodically, plane waves furnish a very convenient basis set over which to expand electronic wavefunctions, at least in inter-cores regions. Since cores are regions of rapidly oscillating amplitudes of the electronic wavefunction (electronic "layers"), the drawback is that many more high frequency (high energy) plane waves are required to describe this multi-nodal region. This implies the diagonalization of huge matrices in order to solve the related eigenvalues problem. For chemical purposes it is legitimate to use the approximation that core electrons remain unaffected by the formation of bonds, which involve the sharing of valence electrons between atoms in the compound. The concept of pseudo-potentials [11, 12], already known by molecular theoretical chemists, has proven very effective in the plane-wave approach: the description of electronic structure is reduced to a set of outer valence electrons (to some extent arbitrarily distinguished), which experience the attractive potentials determined by nuclei screened by core electrons, or pseudo-potentials. Eigenvectors of the Hamiltonian operator for valence electrons in the pseudo-potential are called pseudowavefunctions. Pseudo-potentials are usually constructed for isolated neutral atoms under the constraint that valence pseudo-states match quantitatively the corresponding electronic states solution of the all-electrons Schrödinger equation. Pseudo-potentials may be harder or softer, depending on the core radius involved in the "pseudoïsation": the larger the core radius, the more smoothed out the core oscillations of the electronic density, and the lower the number of plane waves needed to represent the pseudo-wavefunctions. To date, the most efficient mathematical objects using this approach are the so-called non-local "ultrasoft" pseudo-potentials (USPP) introduced by Vanderbilt [12]. However, more recently, some drawbacks of pseudo-potentials have been corrected at a modest extra computational load, with the introduction of a kind of frozen core approximation, within the projected augmented wave (PAW) scheme [13, 14].

Finally, it was found that the LDA, which is a piecewise discretization of the total electronic density, fails in the regions of rapidly varying charge density, such as associated with the formation of covalent bonds. The generalized gradient approximation was introduced as a remedy, whereby the exchange-correlation functional depends not only on the local charge density, but also on its local gradient. Several functional forms have been proposed, but the one proposed in [15] is probably the most popular. The good accuracy of this formulation has been demonstrated against experimental geometries and dissociation energies for a large set of molecular situations, as well as for cristallographic and thermochemical data on solids.

$A b$ initio atomistic simulation indeed must be able to predict accurately the forces exerted on atoms, starting with the electronic ground state. It can then be determined where these atoms sit relative to each other, at zero $\mathrm{K}$ and mechanical equilibrium, what the spring constants are which tie them to their equilibrium positions, and how much energy it takes to break apart a fragment of the edifice. If this is achieved, ab initio molecular dynamics at finite temperature is within reach. The spontaneous trajectories in real space of an ensemble of atoms in interaction, starting from an arbitrary configuration and maintained in thermal equilibrium with a virtual thermostat [16], can be retraced by double numerical integration of Newton's law of motion. Thus, the accurate quantum mechanical determination of the electronic energy bridges a gap with statistical thermophysics, through the numerical resolution of the (time independant) Schrödinger equation, and of its first derivative with respect to the degrees of freedom of the ionic cores according to the Hellmann-Feynmann theorem [17], and ultimately second and higher order derivatives. It provides input to classical thermal and partition functions, in terms of energy levels and normal modes frequencies, in sufficient quality that macroscopic enthalpic and entropic contents are amenable in principle to comparison with experimental data for any system. The dialogue between theory (or rather, computer experiments) and experiment, is from this point established at the relevant level of free energy arguments.

Moreover, vibrational spectra (phonon spectra in solids) are predicted with unprecedented success, to the extent that DFT is becoming a reliable tool for assignation of frequency bands observed in IR and/or Raman experiments. 
The following sections will give various examples of striking quantitative agreement between DFT predictions and thermochemical or spectroscopic data.

Solid-state chemistry and physics have interesting applications in the real world as soon as they venture beyond the ideal realm of perfect crystals and the harmony of Ewald spheres. Defects, surfaces and interfaces, are of major importance to semi-conductor physicists, materials scientists, chemical engineers concerned with heterogeneous catalysts, and ultimately geochemists/geoscientists. To deal with these complications, which involve symmetry reductions, one "trick" was to introduce the so-called "super-cell" technique, which consists in embedding the point-defect or the interface in a larger elementary repeating motive. The space group usually reduces itself to $P 1$, with the loss of symmetry elements inside the Bravais unit-cell, implying an extracomputational load. The latter is however to some extent compensated for by the fact that a larger asymmetric unit-cell has a simpler bandstructure, for which a description by the Gamma-point in the Brillouin zone is often sufficient. The supercell must, however, be large enough so that spurious interactions between defects or interfaces in neighbouring cells are minimized, otherwise the model represents an array of concentrated defects. In most cases, tests of convergence with respect to cell parameters have to be carefully performed. For instance, "slab" models, used to study dissociative chemisorption phenomena at reactive surfaces, must be checked in terms of slab width $(w)$ and interslab distance $(h)$ across the vacuum slit (the repeat distance being $\|\boldsymbol{c}\|=w+h$, so as to ensure that surfaces do not interact across the vacuum or the slab (Fig. 1). The number and disposition of adsorbates per unit-cell determine, in conjunction with cell lateral dimensions, the surface coverage. Symmetries in the plane may be, or must be, exploited, according to the case, and this can determine the size and relative angle of $\mathbf{a}$ and $\mathbf{b}$ unit vectors.

DFT has its known limitations in the present state of the theory: they stem mainly from the absence of a systematic theoretical guideline for improving exchange-correlation functionals, so that the best remain akin to cooking recipees. For instance, LDA overbinds and GGA is systematically better in predicting cohesive energies and barriers, but sometimes the forces and hence geometries are sligthly degraded. Band gaps are systematically too low, by $\sim 40 \%$, due to improperly taking into account the full exchange repulsive potential between filled and empty states. Electronic excited states are not well described within DFT, leading to limitations as far as optical spectra prediction is concerned. However progress is currently under way thanks to the extension known as time dependent DFT [18]. A somewhat related problem of DFT, also rooted in an improper long-range behaviour of functionals, is the poor prediction of the ubiquitous van der Waals (dispersion) attractive forces, which are caused by the long range

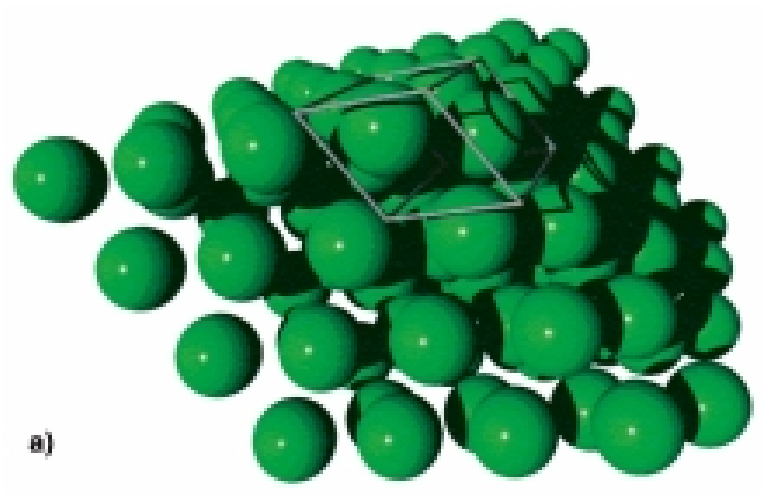

b)
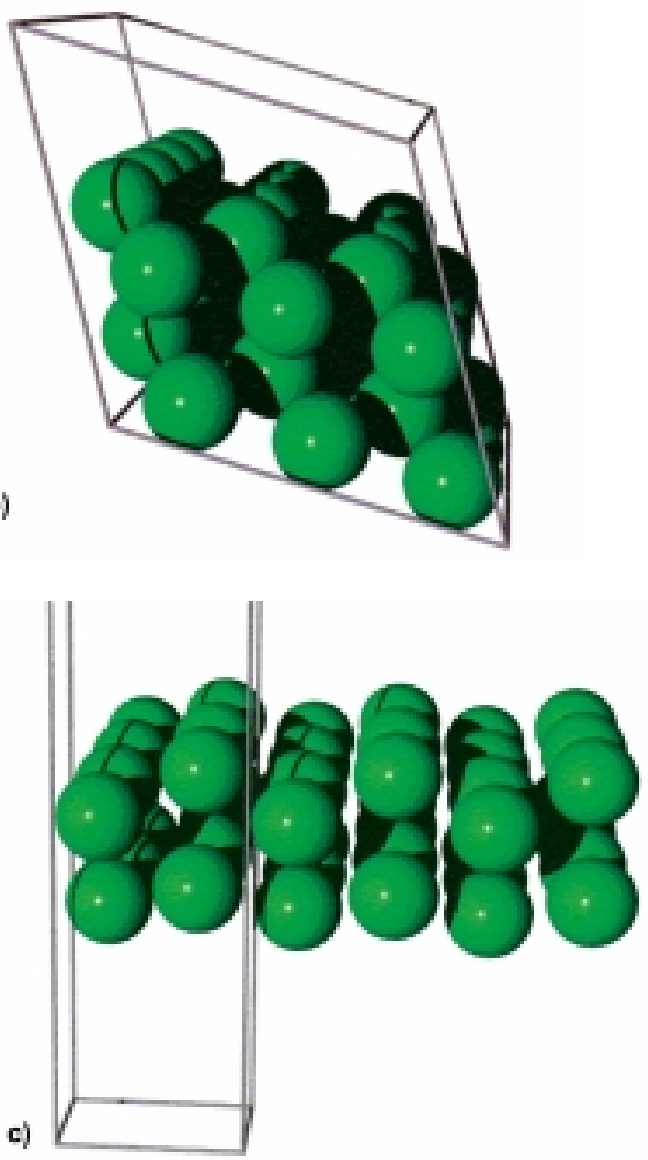

Figure 1

Schematic illustration of the slab configuration used for studying interfaces through the so-called supercells technique with triperiodic DFT quantum mechanical techniques. a) build a bulk supercell by multiplying the symmetric unitcell (Bravais mesh unit-cell) along the three axis. e.g.: hexagonal metal, space group $P 63 / m m c, 4 \times 4 \times 4$ supercell; b) create a slice of width $\mathrm{w}$, terminated by the selected $(h k l)$ plane (here (001); c) determine the new unit-cell with c axis normal to the surface, and new space group $($ e.g. $\mathrm{Cmcm})$. Norm of $c$ equals $w+h$, where $h$ is the interslab distance. This slit of width $h$ is a vacuum, or contains molecules interacting between themselves (fluid phase) and with the solid surface (adsorbed phase). 
correlations of electronic density fluctuations. This defect gains importance when it comes for instance to evaluation of interactions of large molecules with surfaces, or confinement effects in micropores such as for hydrocarbons in molecular sieves [19-21]. Empirical corrections augmenting the DFT interaction energy may in these cases prove useful, for want of further achievements in theory that can be implemented in practice [22].

Despite these limitations, which are also far from fully overcome by its post-Hartree-Fock ab initio alternatives, DFT's quality/cost ratio and its favourable scaling behaviour have determined its tremendous success, as testified by the rapidly increasing volume of breakthrough making papers which has characterized all areas of chemistry and materials science literature for the past 10-15 years. If this success fully justifies the attribution of the 1998 Nobel prize in chemistry to Walter Kohn (a physicist), the major contribution of smart and highly efficient implementations in widely disseminated codes should be equally recognized. To name but the best known:

- VASP (Vienna Ab initio Simulation Package), the most frequently used by our group [23], and CASTEP (Cambridge Ab initio Sequential Total Energy Package) [24], implement the plane wave/pseudopotential approach in $3 \mathrm{D}$ periodic boundary conditions;

- $\mathrm{Dmol}^{3}$ [10], originally a molecular code and later extended to solid-state, expands the electronic wavefunction over accurate numerical atomic orbitals;

- Gaussian [25] and Jaguar [26] expand the wavefunction over gaussian primitives.

All these packages provide geometry optimization and second derivatives outputs, and a variety of property prediction "tools". Optimized compilations have been achieved on almost every platform under the leading operating systems (Unix, Linux, Windows). The choice of a particular code for a particular task is a matter of compromise and experience, taking into account the affordable software and hardware resource and the nature of the problem.

While this section aimed at introducing the reader to some basic notions and vocabulary which hopefully will help him/her to appraise the DFT-based literature invading her/his own specialized field, we provide in the next sections examples, mostly taken from our own research and dealing with minerals and their interfaces with molecular fluids.

\section{BULK THERMODYNAMICS OF MINERALS}

It is logical to first ask the question if DFT is correctly able to predict bulk mineral properties. Figure 2 illustrates the performance of DFT at predicting standard heats of formation of transition metals oxides. The calculations have been performed with the VASP package through the MedeA interface [27], at the PAW/Spin Polarized/GGA-PW91 level.

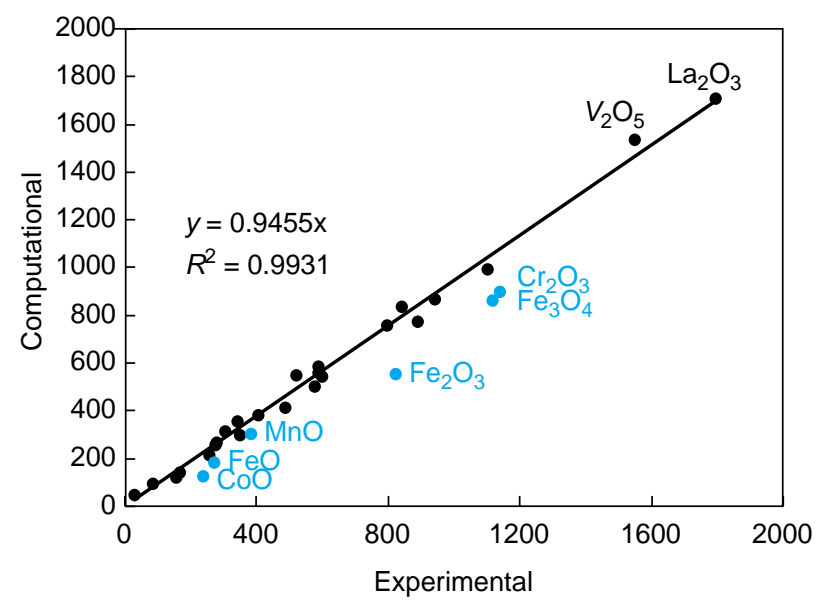

Figure 2

Parity diagram showing the performance of DFT in predicting $a b$ initio the standard heats of formation of oxides across the periodic table (in $\mathrm{kJ} \cdot \mathrm{mol}^{-1}$ ). The calculations include spin polarization in the generalized gradient approximation and the projected augmented wave scheme (VASP code [23] under the MedeA interface [27]). The solid line corresponds to the regression equation and coefficient of correlation shown in inset.

The evaluation of standard heats of formation involves setting up a Born-Haber cycle with the compound and its elements in their standard state, that is gaseous dioxygen and bulk transition metals under $1 \mathrm{~atm}$ at $298.15 \mathrm{~K}$. The calculation is performed only once for dioxygen, giving the total energy for $\mathrm{O}_{2}$ at the choosen level of theory, $E\left(\mathrm{O}_{2}\right)$. Then for each oxide of stoichiometry $\mathrm{M}_{\mathrm{n}} \mathrm{O}_{\mathrm{p}}$ one needs to determine total energies of the bulk unit-cell $E\left(\mathrm{M}_{\mathrm{n}} \mathrm{O}_{\mathrm{p}}\right)$, as well as that of the corresponding metal bulk unit-cell involving $q$ unequivalent atoms per cell $E\left(\mathrm{M}_{\mathrm{q}}\right)$. The cohesive energy contribution to the standard heat of formation is given by:

$$
\Delta E_{f}^{0}=\left[E\left(\mathrm{M}_{\mathrm{n}} \mathrm{O}_{\mathrm{p}}\right)-\frac{n}{q} E\left(\mathrm{M}_{\mathrm{q}}\right)-\frac{p}{2} E\left(\mathrm{O}_{2}\right)\right]
$$

Thermal functions and zero point energy corrections need then to be introduced in this balance. Since these show up as second order corrections to heats of formation of oxides, the data plotted in Figure 2 as a function of experimental values are restrained to the output of Equation (1). There are outliers in the parity diagram (blue dots), for which our DFT calculations were less accurate:

- 3d TM monoxides ( $\mathrm{FeO}, \mathrm{CoO}, \mathrm{MnO}$ ) are relatively poorly described since their structure induces particularly strong electron correlation effects; these materials remain a good benchmark for advanced exchange-correlation functionals;

- for magnetic oxides $\left(\mathrm{Fe}_{2} \mathrm{O}_{3}, \mathrm{Cr}_{2} \mathrm{O}_{3}, \mathrm{Fe}_{3} \mathrm{O}_{4}\right)$, calculations with much larger supercells would be required, taking into account the translational symmetry of spontaneous 
magnetic ordering, in order to recover the associated energetic stabilization.

Apart from these well identified exceptions, the diagram shows an excellent agreement over the full range of TM oxides, although DFT/GGA systematically underestimates the energy of formation by about 5\% (black dots). DFT is therefore fairly predictive and can be used, for instance, to estimate phase boundaries in extreme conditions.

Another class of minerals of significance in earth sciences is that of sulfides: some of us contributed recently to an extensive ab initio study of cohesive properties and electronic structure of transition metal sulfides [28]. In the course of this project, similar results to those shown for oxides in Figure 2 were obtained, in terms of energetic accuracy.

The diversity of aluminum hydroxydes can be encompassed through Equation (2), which expresses formally the hydration equilibria of the most stable aluminum oxide, corundum $\left(\alpha \mathrm{Al}_{2} \mathrm{O}_{3}\right)$ :

$$
\alpha \mathrm{Al}_{2} \mathrm{O}_{3}+x \mathrm{H}_{2} \mathrm{O} \Leftrightarrow\left[\mathrm{Al}_{2} \mathrm{O}_{3}, x \mathrm{H}_{2} \mathrm{O}\right]
$$

According to (2), the Gibbs free energy of formation of a given hydroxide, characterized by a degree of hydration $x$, can be expressed as a function of temperature and chemical potential of water as:

$$
\Delta G(T)=G_{\left[\mathrm{Al}_{2} \mathrm{O}_{3}, x \mathrm{H}_{2} \mathrm{O}\right]}^{s}-G_{\left[\alpha \mathrm{Al}_{2} \mathrm{O}_{3}\right]}^{s}-x \mu_{\mathrm{H}_{2} \mathrm{O}}
$$

With a further approximation, Equation (3) becomes linear in $T$, with all parameters resulting from DFT calculations [29]:

$$
\Delta G(T) \approx E_{\left[\mathrm{Al}_{2} \mathrm{O}_{3}, x \mathrm{H}_{2} \mathrm{O}\right]}^{s}-E_{\left[\alpha \mathrm{Al}_{2} \mathrm{O}_{3}\right]}^{s}-x E_{\mathrm{H}_{2} \mathrm{O}}^{g}+T S_{\mathrm{H}_{2} \mathrm{O}}^{g}
$$

Taking corundum as the reference material, Figure 3, adapted from [29], has been obtained on the basis of Equation (4): it shows the relative stabilities of aluminum hydroxides under one bar of $\mathrm{H}_{2} \mathrm{O}$, as a function of temperature. This theoretical phase diagram is entirely consistent with experiment. Moreover, transition temperatures are precisely defined, at the intersection of lines (e.g. gibbsite $\rightarrow$ diaspore), also in good concordance with experiment. Interestingly, the hypothetical spinel structure $\mathrm{HAl}_{5} \mathrm{O}_{8}$, often proposed for the industrially important $\gamma-\mathrm{Al}_{2} \mathrm{O}_{3}$, a "transition" alumina resulting from dehydration of boehmite, can be ruled out since the predicted transition temperature $(820 \mathrm{~K})$ is much too high. We have addressed elsewhere [30] the topotactic transition from boehmite into a much more relevant new structure for $\gamma-\mathrm{Al}_{2} \mathrm{O}_{3}$.

These are but a few selected examples of the usefulness of DFT simulations as a possible complement, or supplement, to experimental studies of, for instance, hydrothermal equilibria involving minerals. Simulations can also provide a good deal of insight in the case of solid solutions, which are of paramount importance in mineralogy: the problem here is

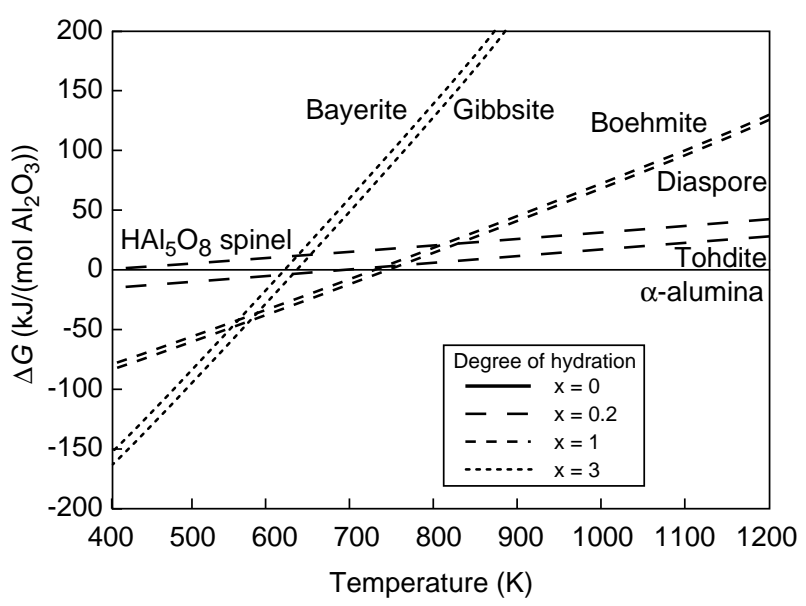

Figure 3

$A b$ initio phase diagram showing the relative stability of aluminum hydroxides, referred to corundum, as a function of temperature under 1 bar of water (adapted from [29]).

to define a unit-cell of size amenable to calculations within a reasonable allocation of resources. In most cases, the solid solution is crystallographically definable only in a statistical sense, for instance with fractional occupation numbers. Modern statistical theory of alloys, such as the cluster expansion approach [31] provide a good angle of attack. In essence, this kind of "divide and conquer" method consists in viewing the disordered solid as a statistical realization of a superposition of locally ordered configurations, each characterized by a small unit-cell easily tractable in DFT. The next step is to evaluate a database of "effective cluster interactions", still at the DFT level, by combining small sub unit-cells to form larger super-cells. Finally, the properties of the real solid at a given temperature are evaluated through Monte-Carlo simulations, designed to produce the correct statistical weights of all locally ordered configurations in the globally disordered solid. One of us has fairly successfully implemented this approach [32] in a test case study of the substitution of $\mathrm{Mg}^{2+}$ cations by $\mathrm{Al}^{3+}$ cations in tetrahedral positions of the spinel $\mathrm{MgAl}_{2} \mathrm{O}_{4}$ (spinel inversion).

\section{SURFACE THERMODYNAMICS OF MINERALS}

Fluid and minerals interact at mineral surfaces. The physicochemical properties of the latter differ from those of the bulk to some extent, since surface atoms experience an incomplete or different coordination from their counterparts in the bulk. The most needed quantities when it comes to study surface phenomena are interfacial free energies $\gamma_{h k l}\left(\mathrm{~J} \cdot \mathrm{m}^{-2}\right)$. The indices $h, k, l$ denote the Miller indices of the particular surface considered, that is the coordinates of the unit vector normal to that surface relative to the system of coordinates formed by the three unit vectors of the unit-cell of the solid. 
The surface of a solid is in essence metastable, however, the shape of a crystal tends to minimize the overall surface free energy. Facets with the lowest surface energy will therefore tend to dominate the morphology, whatever the length scale spanned by the growing or dissolving crystallite. Adsorption of constituents from the fluid phase occurs spontaneously when it contributes to a lowering of the interfacial energies (Gibbs law of adsorption). Adsorption from the fluid phase will affect significantly the thermodynamics and kinetics of growth and dissolution phenomena.

Solid-fluid interfacial energies, most often measured by calorimetric methods, are quite difficult to measure accurately and reproducibly. Since large surface areas are needed to increase signal/noise ratios, the experiments require highly divided solids leading to multiple orientations of facets. Moreover, adsorption of impurities will interfere all the more as the solid is increasingly divided. Experimental surface science has invested greatly in the development of technologies allowing the preparation of well defined and clean solid surfaces and recently exquisite, almost molecularly resolved, calorimetric techniques have brought fresh data on the chemisorption of simple gases on such surfaces as a function of coverage [33]. We are nevertheless still far from a direct experimental molecular description of interactions at liquid-solid interfaces.

By contrast, two unique advantages of DFT are that it allows of such problems to be tackled, and that it performs particularly well as far as the "chemical" part of the free energy (dissipated on creation of a liquid solid interface) is concerned. This major contribution to interfacial free energies has been largely overlooked so far, although it determines the stable structure of the extreme surface layer, and as a consequence the structure of the adsorption layer on the liquid side, in the sense defined by Gibbs. For instance, as will be detailed below, the creation of interfaces between a solid oxide and water involve, in a thought experiment:

1. Cleavage of the perfect infinite crystal along one plane of indices $(h, k, l)$ in vacuum, against cohesive energy.

2. Dissipation of surface energy to reconstruct the freshly cleaved planes under vacuum.

3. Dissipation of chemical energy and entropy through the coverage of surfaces by water molecules, involving sequentially as coverage increases from zero up to a monolayer, dissociative chemisorption (and chemisorption induced de-reconstruction), followed by molecular chemisorption, then molecular physisorption, and intermolecular interactions within the surface layer, mainly due to hydrogen bonding.

4. Structuration of the first liquid layer in interaction with the adsorbed layer through hydrogen bonding, against entropy.

5. Longer range perturbation of the layer of bulk liquid proximal to the surface.
Since DFT simulations by the supercells technique is restricted to neutral systems (each supercell must be globally neutral, whereas charge separation within the cell is allowed), the final state of the simulated system will correspond to the interface with water at zero point charge (ZPC).

This virtual pathway is diagrammatically illustrated in Figure 4, which shows the straightforward free energy balance leading to an evaluation of a liquid-solid interfacial energy.

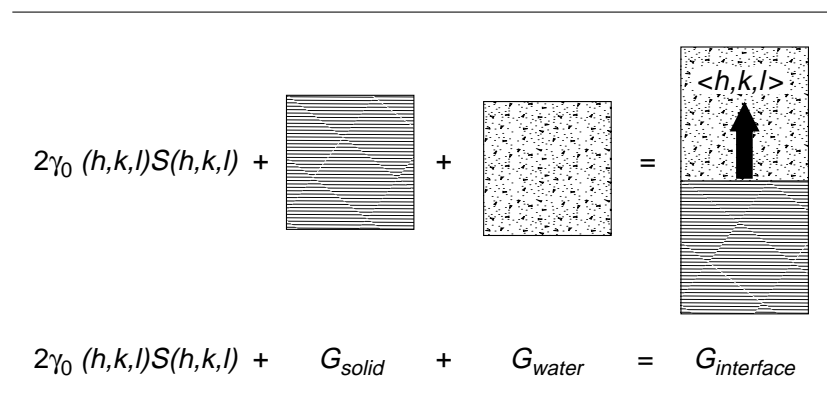

Figure 4

Schematic illustration of the Born-Haber cycle involved in the $a b$ initio evaluation of interfacial energies.

We have successfully applied this strategy for a recent DFT study of water-boehmite (AlOOH) interfaces [34]. Boehmite is a key material in the production of ultra-pure transition aluminas of very high surface areas. As supports and dispersers of noble metals agregates, heavy transition metals oxides or sulfides nanoparticles, these constitute the bulk of heterogeneous catalysts currently in use in the refining and petrochemical industries, as well as in automotive exhaust catalytic converters. Boehmite is prepared industrially by neutralization of aluminum salts in aqueous solution, in conditions favouring the formation of nanosized crystallites (an example of early "nanotechnology"). Boehmite dehydrates topotactically into $\gamma$-alumina, that is the nanosized crystallite morphology and size are almost exactly preserved. It is therefore crucial to control the morphologies at the precipitation and ripening stages, in order to control the desired textural properties (surface area, pore size distribution, pore connectivities) of the final product. Not less important, the acid-base properties of boehmite, as well as those of the final alumina, are also morphology dependent, as will be shown, and also play a central role in the further stages of the preparation of the catalysts, which involve adsorption and/or ion exchange from solutions of compounds of the active transition elements.

To treat this case, we have used ab initio molecular dynamics in order to allow the as-cleaved oriented models of boehmite surfaces to reactively equilibrate at $350 \mathrm{~K}$ (the temperature at which boehmite synthesis is performed) with layers of liquid water, that is at a density corresponding to the chemical potential of bulk water. Despite its extreme 
computational intensiveness, it was essential to use a theoretical method allowing the dynamical breaking and formation of chemical bonds, while simulateously allowing fluctuations in local kinetic energy to overcome reaction barriers, and therefore sample correctly the phase space accessible to the systems. Classical molecular dynamic methods relying solely on empirical forcefields are of little use in this respect. Figure 5 shows the evolution of computed interfacial tensions (IFT) for the selected surface orientations. A progression of IFTs with time towards a stable average is observed, while the initially decreasing trends reflect precisely the dissipation (by exchange of excess kinetic energy with a virtual thermostat) of chemical energy in excess, through the reaction of water molecules with coordinatively unsaturated surface aluminum and oxygen atoms, producing surface hydroxyl groups. This dissipation is absent for the (010) orientation: the initial surface is already saturated by hydroxyls, as it corresponds to a cleavage along the hydrogen bonded sheets of this lamellar solid. These surfaces re-equilibrate with liquid water only by re-arranging a network of hydrogen bonds, an almost athermal process compared with the reactive processes implied for other planes of cleavage. Figures $6 \mathrm{a}$ and $6 \mathrm{~b}$ illustrate the initial (as cleaved in vacuum) and final configurations for the (010) and (101) orientations respectively. The computed IFT results are summarized in Table 1. Note the significant systematic decrease of IFTs on going from vacuum to water, excepted in the $(010)$ case: the solids surfaces are, as is expected but generally overlooked, strongly stabilized by their reaction with species from the liquid phase. The reacted boehmite surfaces are expected to present a strong hydrophilic character, since they are covered with a high density of hydroxyl groups.

TABLE 1

Computed surface and interfacial tensions for the boehmite/vacuum and boehmite/water system in units of $\mathrm{J} \cdot \mathrm{m}^{-2}$ (adapted from [34])

\begin{tabular}{c|c|c}
\hline Orientation (Miller notation) & $\gamma_{\mathrm{V}}(0 \mathrm{~K})$ & $\gamma_{\mathrm{SW}}(0 \mathrm{~K})$ \\
\hline$(010)$ & 0.45 & 0.47 \\
$(100)$ & 1.86 & 0.65 \\
$(001)$ & 1.16 & 0.75 \\
$(101)$ & 3.04 & 0.82 \\
\hline
\end{tabular}

Once the IFTs are known for the denser planes of a mineral, it is possible to predict its morphology at equilibrium through the simple Gibbs-Curie-Wulff construction [35]. This construction solves the problem of finding the shape of minimal surface energy for a polyhedron, knowing the surface energy densities $\gamma_{h k l}$ for each orientation: the Lagrange multiplier method provides the simple solution that IFTs ratios are proportional to the ratios of distances $d_{h k l}$ of $(h k l)$ facets to the crystal's center:

$$
\frac{\gamma_{i j k}}{\gamma_{l m n}}=\frac{d_{i j k}}{d_{l m n}}(i, j, k) \neq(k, l, m)
$$

As shown in Figure 7, the equilibrium shape is the polyhedral envelope defined by the set of intersecting $(h k l)$ planes perpendicular to the set of segments of common origin, colinear to the $(h k l)$ unit vectors, and of length
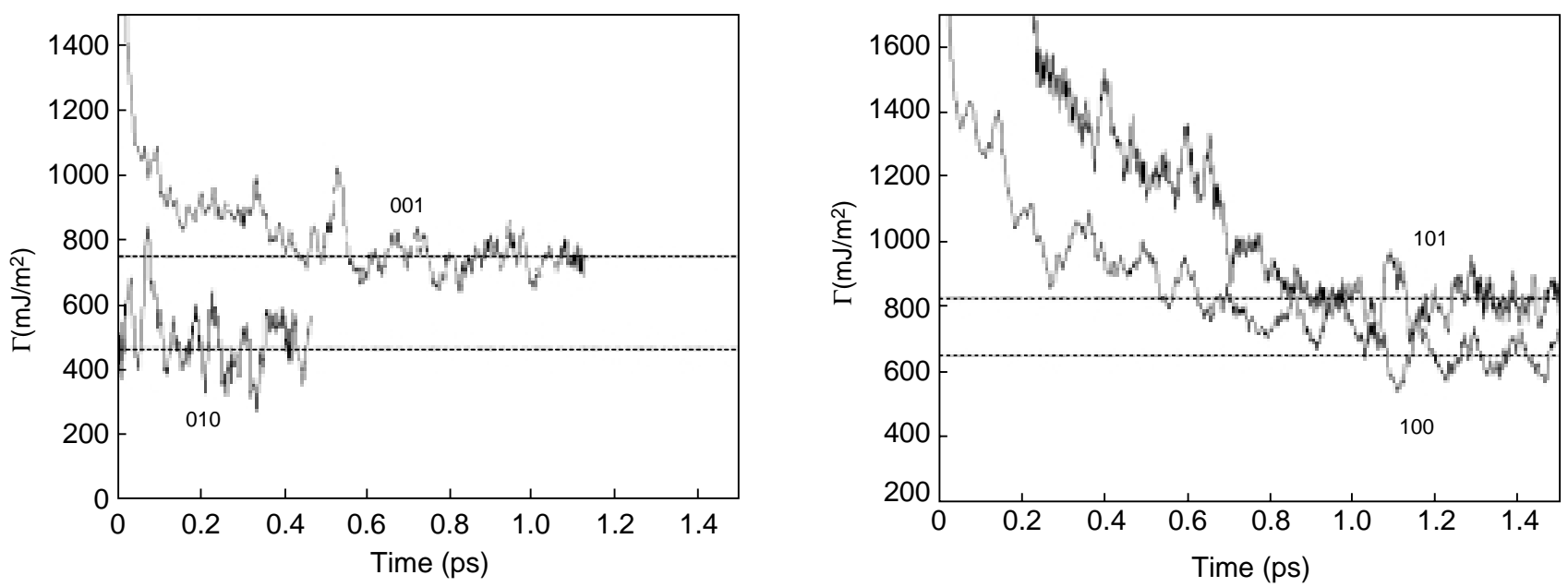

Figure 5

Evolution of computed water/boehmite $(h k l)$ interfacial energies with time of $a b$ initio molecular dynamics runs. The time step is $1 \mathrm{fs}\left(10^{-15} \mathrm{~s}\right)$. Each run has a duration of the order of $1 \mathrm{ps}\left(10^{-12} \mathrm{~s}\right)$. The unreactive (010) basal surface equilibrates in less than $0.2 \mathrm{ps}$, while the other ascleaved initially highly coordinatively unsaturated surfaces need at least of the order of 1 ps to equilibrate. These "slow" approaches to equilibrium involve dissociative chemisorption events of water molecules at the interface (adapted from [34]). 


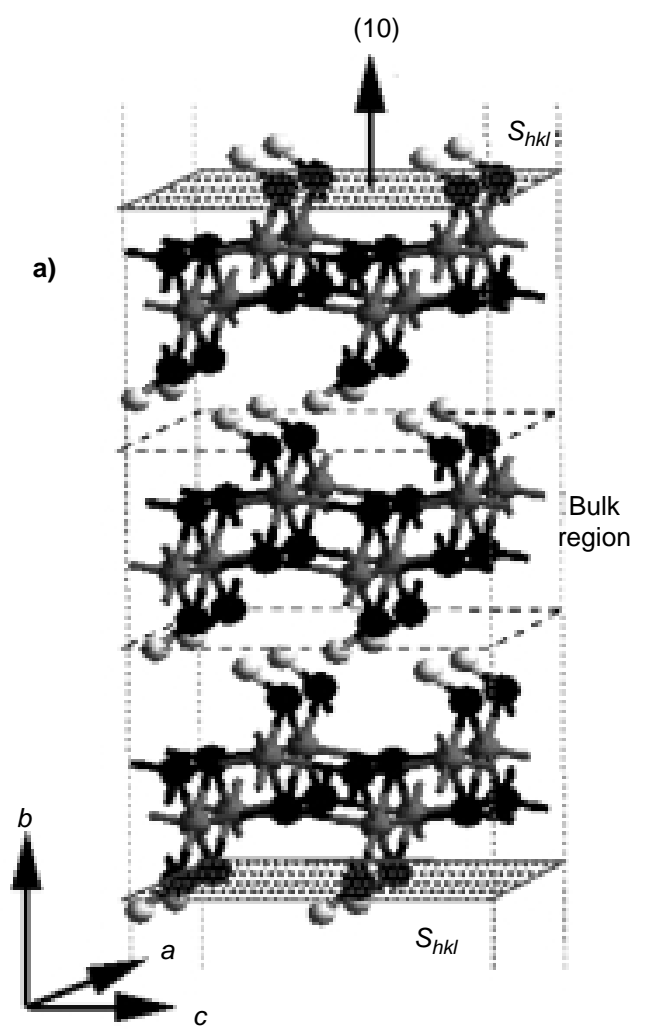

b)

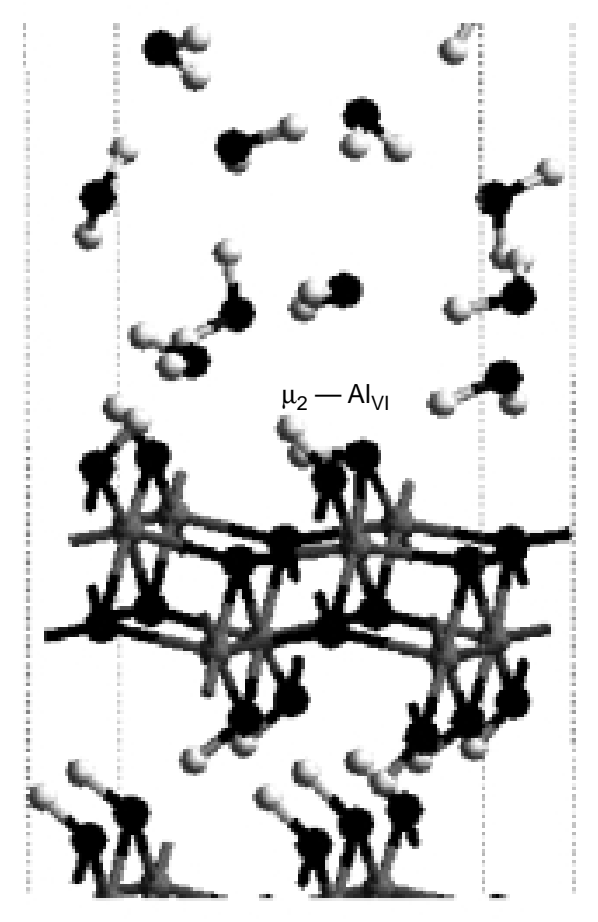

Figure 6

Snapshots of a) initial (010) cell, and b) equilibrium configurations at the water/boehmite (010) and (101) interfaces (adapted from [34]).

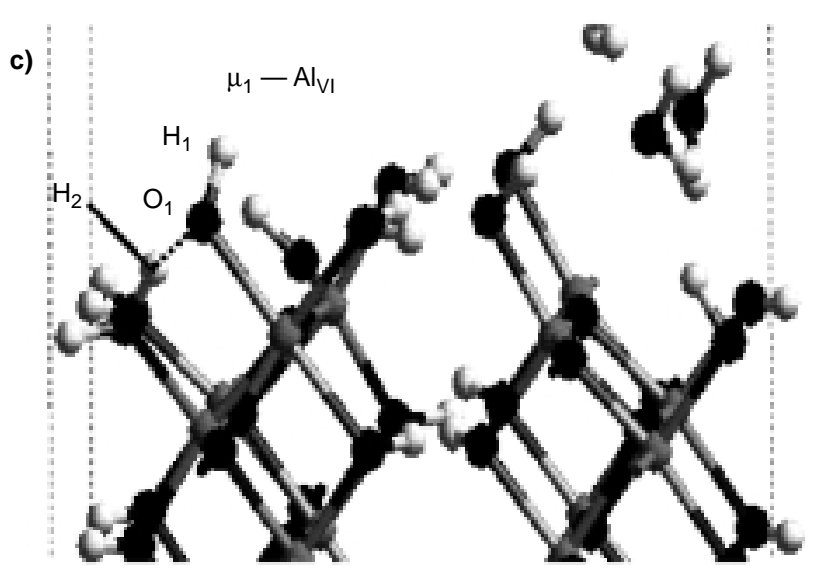

proportional to $\gamma_{h k l}$. The equilibrium polyhedron vertices are the lines of intersection of these envelopping planes.

Figure 8 shows the predicted equilibrium morphologies for boehmite in vacuum and in water at $350 \mathrm{~K}$ at, as emphasized above, the $\mathrm{pH}$ of zero point charge (ZPC). The $\mathrm{pH}$ of synthesis is an important controlling parameter, as shown by electron micrographs in Figure 9, [36], with elongated nanocristallites being formed at neutral to mildly acidic conditions, and roughly square platelets under basic conditions. The effect of proton adsorption on IFTs as a function of $\mathrm{pH}$ can be predicted using a model taking into account the Gibbs law of adsorption, as well as the free energy associated with the formation of the diffuse ionic double-layer in the Grahame formulation [36]. These contributions appear however as corrections to the IFTs at ZPC, as expressed in Equation (6).

$$
\begin{array}{ll}
\gamma_{h k l}\left(\sigma_{0}, T, I\right)=\gamma_{h k l}(0, T)+\frac{R T}{F}\left(0.22 \sqrt{I}-2 \sqrt{0.0136 I+\sigma_{0}^{2}}-\sigma_{\max }^{-} \ln \left(1-\frac{\sigma_{0}}{\sigma_{\text {max }}^{-}}\right)\right) & \mathrm{pH}<\mathrm{ZPC} \\
\gamma_{h k l}\left(\sigma_{0}, T, I\right)=\gamma_{h k l}(0, T)+\frac{R T}{F}\left(0.22 \sqrt{I}-2 \sqrt{0.0136 I+\sigma_{0}^{2}}+\sigma_{\max }^{+} \ln \left(1-\frac{\sigma_{0}}{\sigma_{\max }^{+}}\right)\right) & \mathrm{pH}>\mathrm{ZPC}
\end{array}
$$




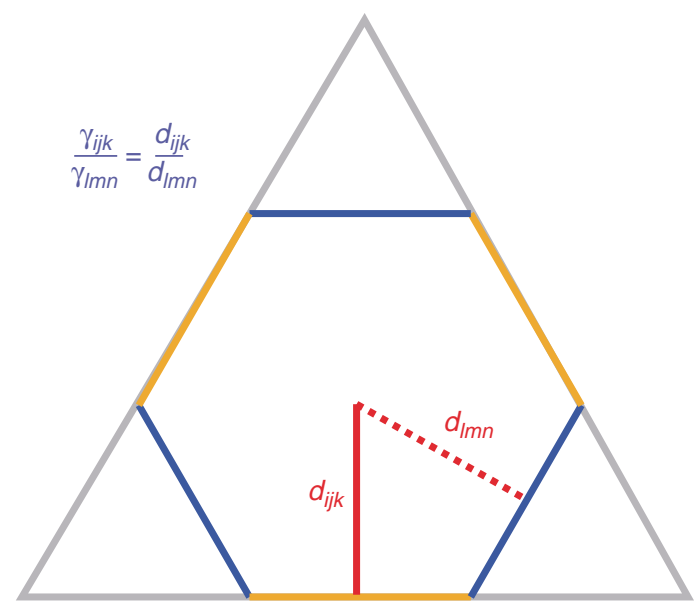

Figure 7

Schematic illustration of the Gibbs-Curie-Wulff construction of equilibrium morphologies of crystalline solids.

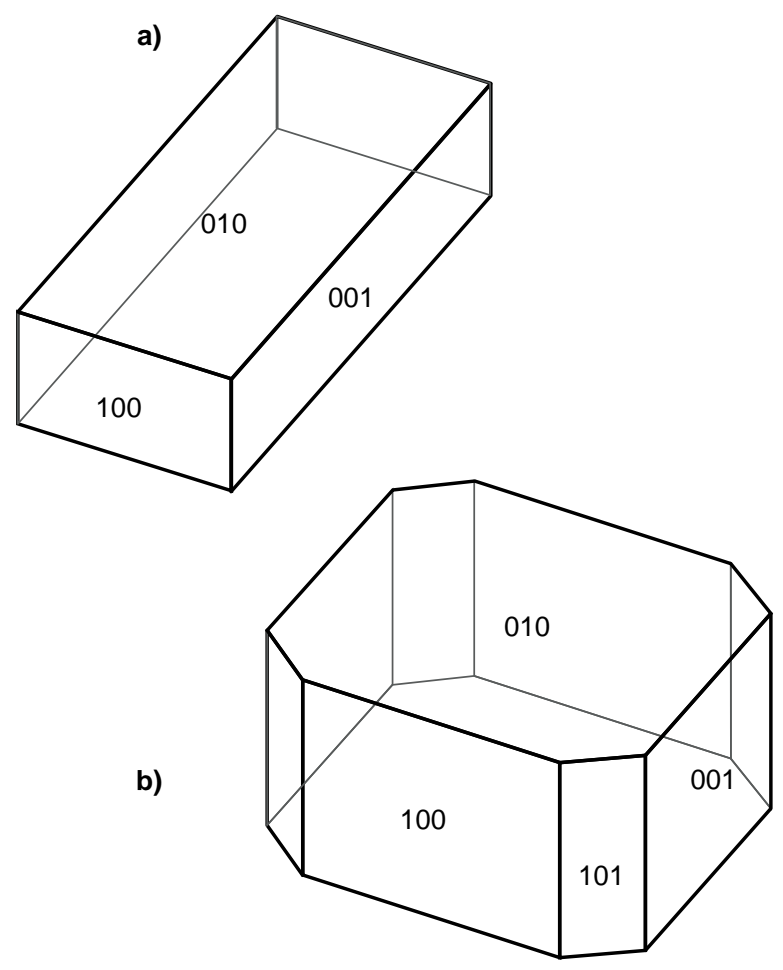

Figure 8

Equilibrium morphologies of boehmite as predicted from the Gibbs-Curie-Wulff contruction using data from Table 1. a) in vacuum; b) in water at $\mathrm{ZPC}$ and $350 \mathrm{~K}$

In Equation (6), $I$ stands for the ionic force in solution, $\sigma_{0}$ for the total surface charge density, $\sigma_{\max }^{-}$and $\sigma_{\max }^{+}$ respectively the maximum negative and positive charge densities, $T$ for temperature, $R$ for the molar ideal gas constant and $F$ for the faraday. Figure 10 illustrates the $\mathrm{pH}$
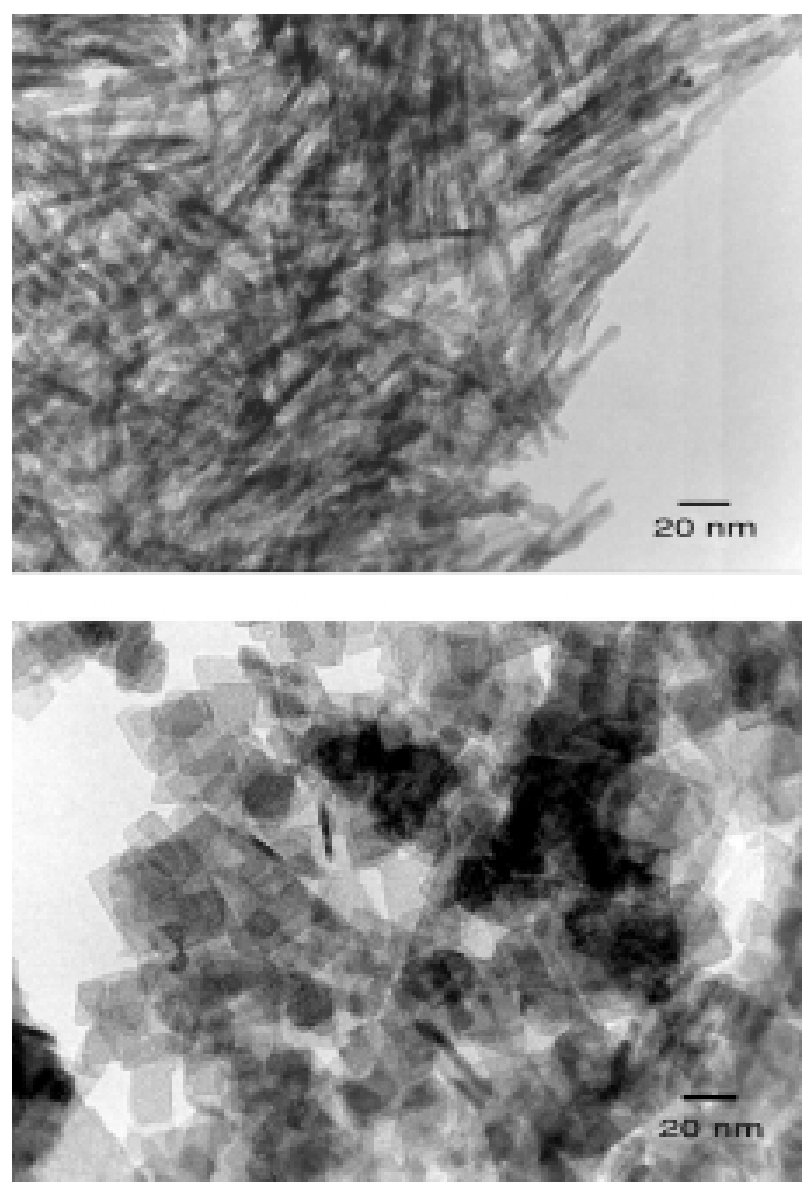

Figure 9

Electron micrographs of boehmite synthetized at different $\mathrm{pH}$ values (adapted from [36]): top: $\mathrm{pH}=8$; bottom: $\mathrm{pH}=11$.

dependencies of IFTs for relevant orientations of boehmitewater interfaces. According to (6), these curves present maxima at the isoelectric point $p I\left(\mathrm{pH}=p I, \sigma_{0}=0 \mathrm{C} \cdot \mathrm{m}^{-2}\right)$. Morphologies at $\mathrm{pH}=8$ and $\mathrm{pH}=11$ can be constructed from the corrected IFTs, as shown in Figure 11, and compared to morphologies via the aspect ratio evaluated from line broadenings in experimental X-Ray diffraction patterns, as well as the morphologies directly observed by TEM (Fig. 9). The overall agreement is excellent, demonstrating the consistency of the approach and the value of the $a b$ initio input.

At this stage, it is worth coming back to the problem of surface speciation of minerals as a function of chemical potentials in gas phase. Carrying out ab initio MD simulations to sample the equilibrium configurations in presence of liquid water amounts to some extent to the use of brute force. It is more informative to describe stepwise the surface congurations along the adsorption isotherms, that is when varying chemical potential from large negative values up to a phase boundary limit, such as that of liquid water. 


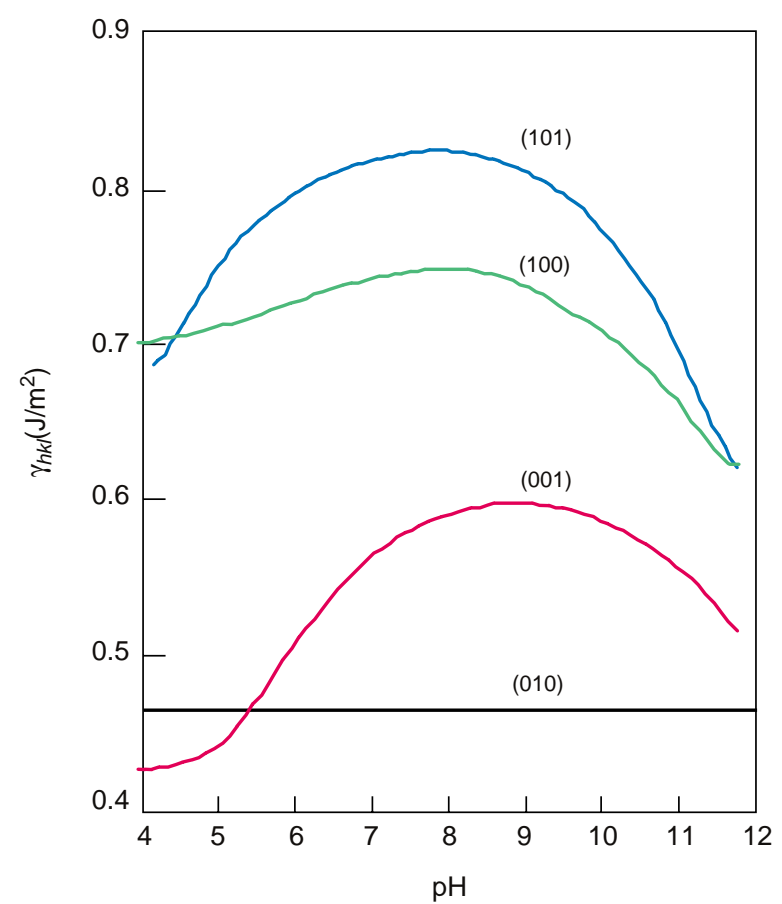

Figure 10

Effect of $\mathrm{pH}$ on orientation dependant interfacial tensions, as predicted by the Froidefond model [36]. The maximal ordinates of these curves are located according to the $a b$ initio computed interfacial tensions at the isoelectric point, $\gamma_{0}(h k l)$, as presented in Table 1 .

The technique derives straightforwardly from the definition of chemical potential of species $i$ as the partial derivative of free energy with respect to the number of moles of $i$ in the system [37]. In the case of hydration by water for instance, neglecting the variation of entropy and $p V$ terms for the condensed phase, as well as thermal variations of internal energies, the surface energy of the $(h k l)$ facet can be expressed as:

$$
\gamma_{h k l}=\gamma_{h k l}^{0}+\theta_{h k l}\left(E_{a d s}-\Delta \mu_{\mathrm{H}_{2} \mathrm{O}}\right)
$$

where $\gamma_{h k l}^{0}$ stands for the surface energy of the fully dehydrated surface, defined by Equation (8). In the latter, $G\left(s_{i r f} f_{h k l}\right)$ represents the Gibbs free energy and $A_{h k l}$ the area of face ( $h k l)$ per unit-cell of slab, while $G(b u l k)$ represents the Gibbs free energy of the corresponding initially uncleaved bulk unit-cell. $\gamma_{h k l}^{0}$ can be finally approximated by (9) where $E_{0 K}$ is the total energy par unit-cell at zero $K$ computed at the DFT level:

$$
\begin{gathered}
\gamma_{h k l}^{0}=\frac{\left[G\left(\operatorname{surf}_{h k l}\right)-G(\text { bulk })\right]}{A_{h k l}} \\
\gamma_{h k l}^{0} \approx \frac{\left[E_{0 K}\left(\operatorname{surf}_{h k l}\right)-E_{0 K}\left(b_{u l k}\right)\right]}{A_{h k l}}
\end{gathered}
$$

In addition, in Equation (7), $E_{a d s}$ stands for the average adsorption energy of $n$ water molecules $\lambda=\left(\theta_{h k l}=\frac{n}{A_{h k l}}\right)$, irrespective of the mode of adorption, and is approximated as:

$$
E_{a d s}=\frac{\left[E_{0 K}\left(\operatorname{surf} f_{h k l}+n \mathrm{H}_{2} \mathrm{O}\right)-E_{0 K}\left(\operatorname{surf}_{h k l}\right)-n E\left(\mathrm{H}_{2} \mathrm{O}\right)\right]}{n}
$$

Finally, $\Delta \mu_{\mathrm{H}_{2} \mathrm{O}}$ is the difference between the chemical potential of water and the internal energy of an isolated water molecule $e_{\mathrm{H}_{2} \mathrm{O}}$, and one can write, in the ideal gas approximation:

$$
\Delta \mu_{\mathrm{H}_{2} \mathrm{O}}=R T \ln \left(\frac{P_{\mathrm{H}_{2} \mathrm{O}}}{P_{0}}\right)+h_{\mathrm{H}_{2} \mathrm{O}}^{0}-T s_{\mathrm{H}_{2} \mathrm{O}}^{0}-e_{\mathrm{H}_{2} \mathrm{O}}
$$
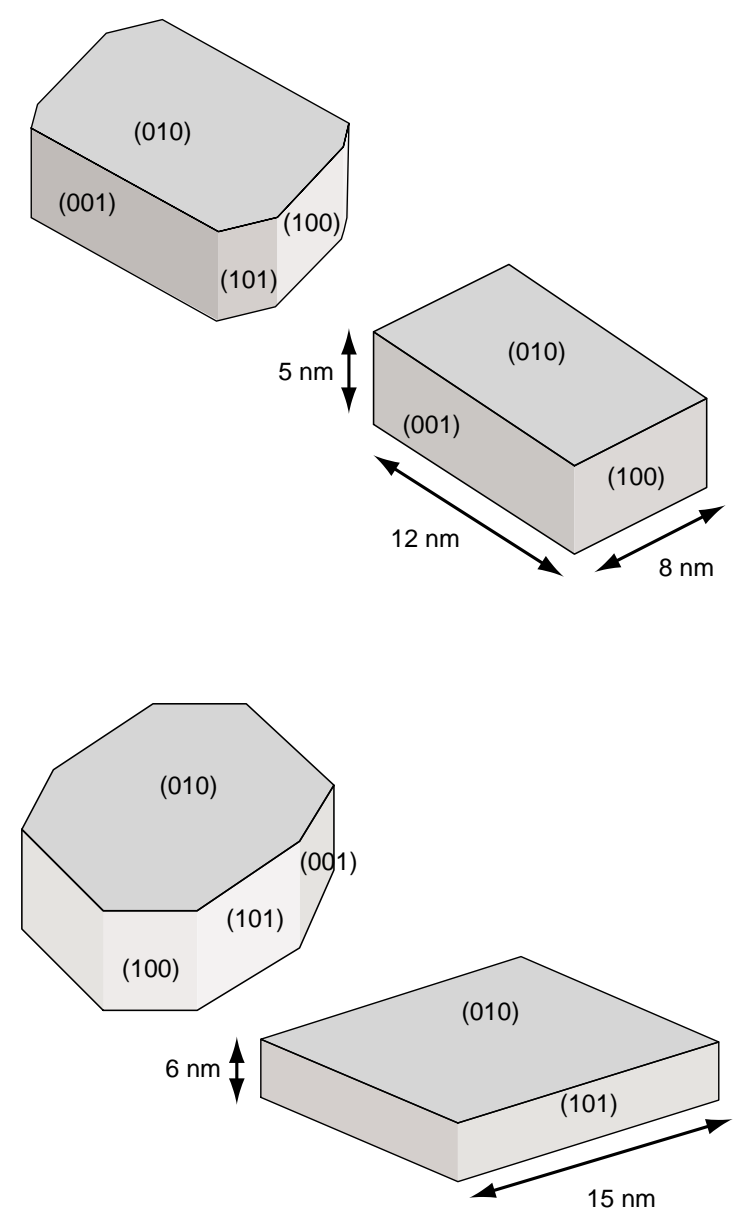

Figure 11

Comparison of $a b$ initio predicted (left) and "observed" (right) morphologies of boehmites synthetized at $\mathrm{pH}=8$ (top) and $\mathrm{pH}=11$ (bottom). The "observed" models result from a fit of the theoretical versus experimental X-ray diffraction spectra (adapted from [36]). 
In Equation (11), $P_{\mathrm{H}_{2} \mathrm{O}}$ is the partial pressure of water, and $P_{0}$ the reference pressure, while other terms can be accurately evaluated by DFT for an isolated water molecule. Equations (8-11) can be easily generalized to multicomponent fluids and therefore to the case of a composite adsorption layer, allowing the effect of fluid phase composition on the surface speciation and equilibrium morphologies of minerals to be discussed. Provided the supercells involved in computations remain globally neutral, there is in principle no obstacle to study along these lines the interaction of electrolytes with mineral surfaces. We have recently applied this technique to study the simultaneous effects of $\mathrm{H}_{2} \mathrm{O}, \mathrm{H}_{2} \mathrm{~S}$ and $\mathrm{H}_{2}$ on anatase $\mathrm{TiO}_{2}$ [38]. In Figure 12 we show how adsorption energies of $\mathrm{H}_{2} \mathrm{~S}$ and $\mathrm{H}_{2} \mathrm{O}$ vary with increasing coverage, when these components are brought separately into the presence of the anatase (001) surface: the general trend is, as expected, a decrease of exothermicity as coverage increases incrementally. In the case of water, the first molecules are dissociatively chemisorbed on surface Lewis acid-base pairs (coordinatively unsaturated $\mathrm{Ti}^{4+}$ and $\mathrm{O}^{2-}$ ions respectively), until saturation of undercoordinated surface Ti ions, $(\theta=3.46$ $\left.\mathrm{H}_{2} \mathrm{O} \cdot \mathrm{nm}^{-2}\right)$. Further adsorbates are then physisorbed (hydrogen bonded). In the case of $\mathrm{H}_{2} \mathrm{~S}$, we observe at the onset of adsorption a complex process. Two Ti-O bond break and two Ti-S bonds form, while the two $\mathrm{H}$ from $\mathrm{H}_{2} \mathrm{~S}$ are transferred to the pending oxygens, resulting in two pendant hydroxyl groups and a Ti-S-Ti bridge: in other terms a superficial sulfidation of anatase coupled to hydration. The next $\mathrm{H}_{2} \mathrm{~S}$ will again dissociatively chemisorb, with insertion of a sulfur atom in a second surface Ti-S-Ti bridge, and transfer of protons to adjacent hydroxyls, leaving two molecularly chemisorbed water molecules on the coordinatively unsaturated sites (CUS) consisting in Ti ions. The following $\mathrm{H}_{2} \mathrm{~S}$ molecules adsorb weakly, but are stabilized by hydrogen bonds involving both the surface sulfur atoms and the molecularly chemisorbed water molecules, products of the superficial sulfidation of anatase. The superficial sulfidation of anatase by $\mathrm{H}_{2} \mathrm{~S}$ has been recently observed experimentally by XPS [39].

When several reactive components in gas phase lead to a modification of the surface, the generalized Equations (8-11) allow multidimensional surface phase diagrams to be determined. When chemical potentials (or equivalently, fugacities in fluid phase) are taken as control parameters, the stable surface corresponding to any set of externally imposed conditions is that with the lowest surface energy. For a given $(\mathrm{hkl})$ orientation, and at a given temperature, surface energies can be represented as hyperplanes in multidimensional space, where energy is one dimension and chemical potentials the others. The surface phase diagram is derived from the projection of the lower envelope of intersecting planes

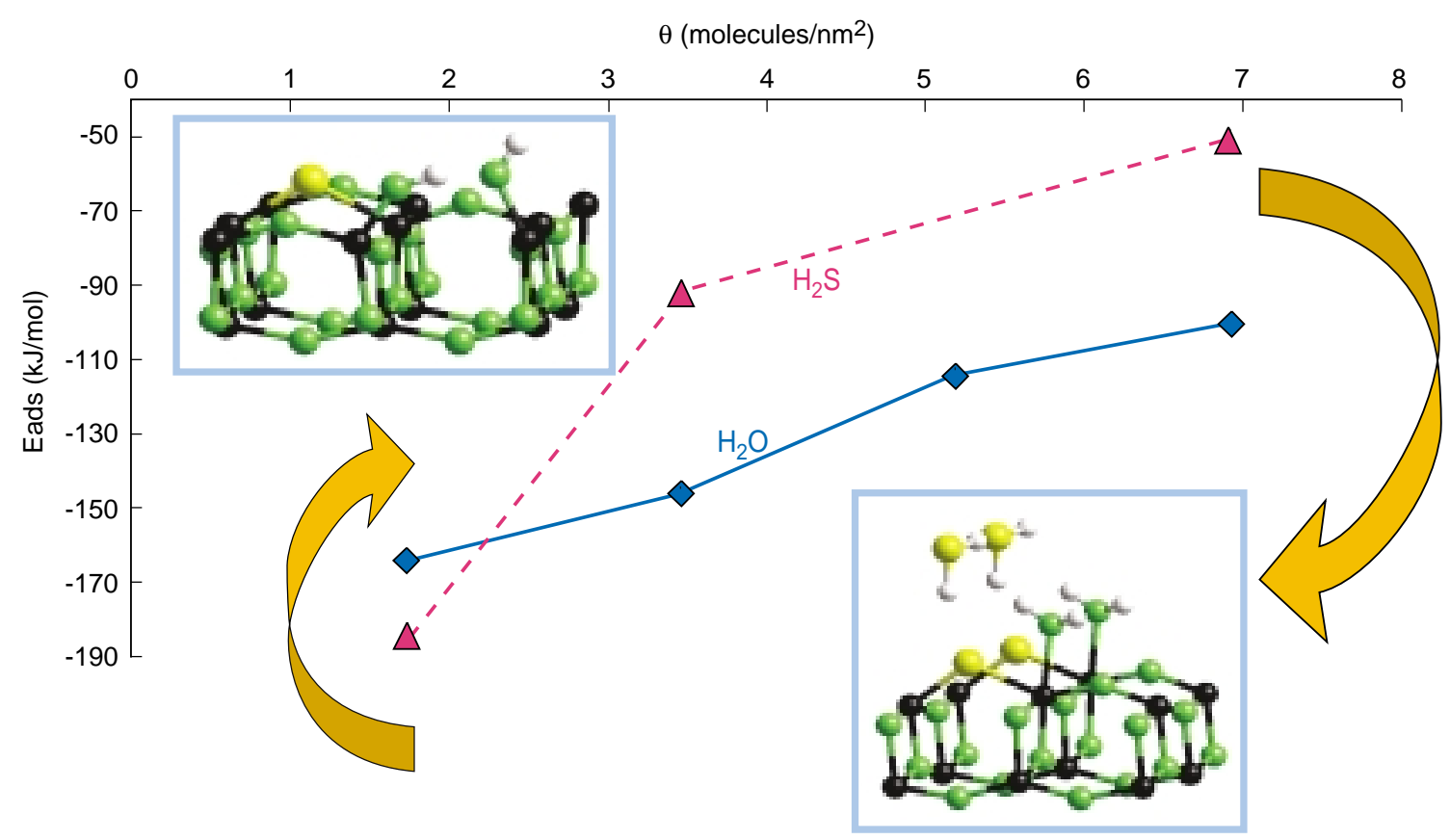

Figure 12

Ab initio computed heats of adsorption of $\mathrm{H}_{2} \mathrm{~S}$ and $\mathrm{H}_{2} \mathrm{O}$ on the (001) surface of $\mathrm{TiO}_{2}$ anatase, as a function of coverage $\theta$ (molecules.nm ${ }^{-2}$ ) (adapted from [38]). Adsorption is dissociative at low coverage. The dissociative adsorption of the first $\mathrm{H}_{2} \mathrm{~S}$ molecule leads to the substitution of one bridging surface oxygen by a sulfur atom, while two $\mu_{1}$ hydroxyl groups are created as products of breaking nearby Ti-O bonds. This surface sulfidation has been observed experimentally by XPS [39]. 

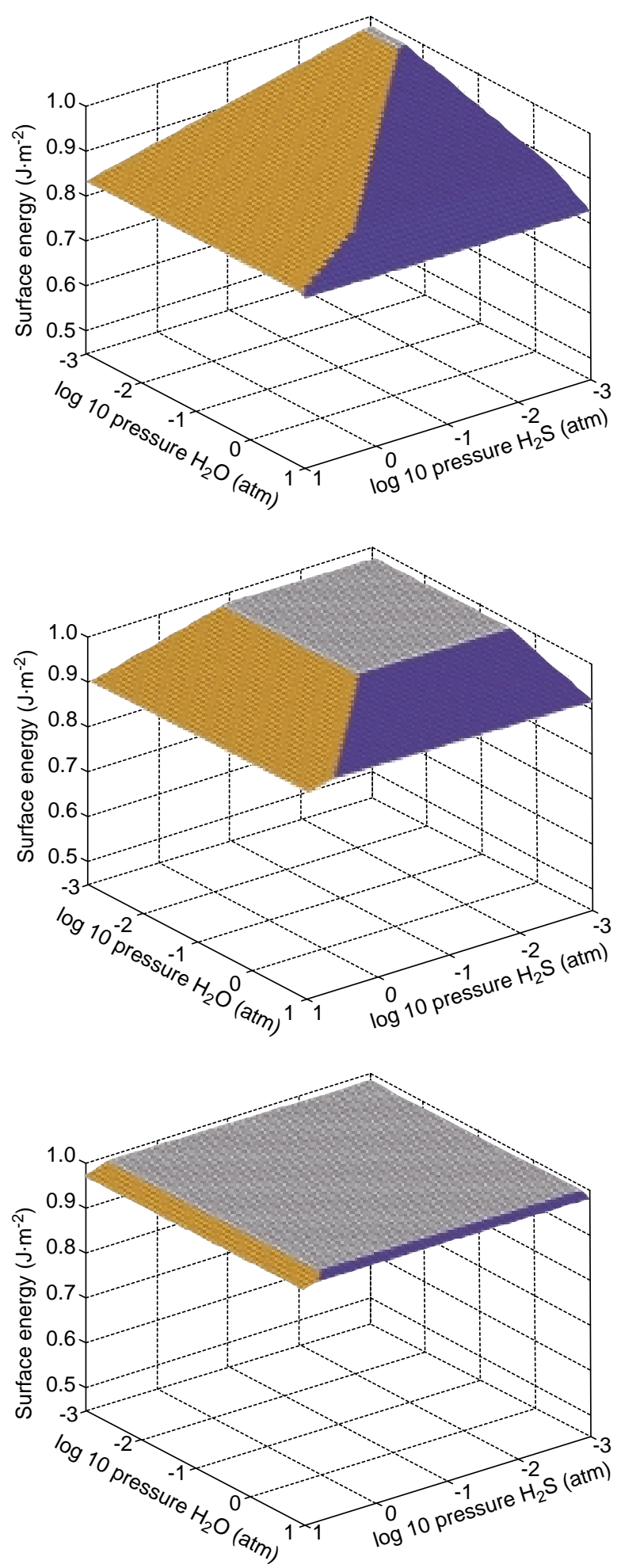

Figure 13

Effect of temperature on the extent of sulfidation and hydroxylation of the (001) surface of $\mathrm{TiO}_{2}$ anatase, as a function of prevailing partial pressures of $\mathrm{H}_{2} \mathrm{~S}$ and $\mathrm{H}_{2} \mathrm{O}$ (adapted from [38]). From top to bottom: $700 \mathrm{~K}, 800 \mathrm{~K}$, $900 \mathrm{~K}$. Blue: hydroxylated; orange: sulfided; grey: bare. along the surface energy coordinate. This is illustrated in 3D on Figure 13 where these envelopes are represented for the (001) plane of anatase as a function of $\log _{10}\left(P_{\mathrm{H}_{2} \mathrm{O}}\right)$ and $\log _{10}\left(P_{\mathrm{H}_{2} \mathrm{~S}}\right)$ for three temperatures. The figure demonstrates the progressive extension of the domain of dehydroxylation and desulfidation of this surface with increasing temperature, and allows the conditions of superficial sulfidation to be delimited.

\section{VIBRATIONAL SPECTRA AT SOLID INTERFACES}

As mentioned in the methodological section, DFT is able to describe accurately both the potential energy hypersurface of a collection of atoms as a function of the nuclear coordinates, and the first and second derivatives of this hypersurface with respect to atomic displacements. It is therefore able to predict the frequencies of normal modes of vibration, corresponding to vibrational spectra as recorded by infrared and Raman spectroscopic techniques.

These techniques have proved considerably useful in characterizing solid surfaces and adsorbed materials at surfaces. Along similar lines, the differences in spectra of free and adsorbed probe molecules are widely used to characterize specific properties of surfaces. Although a considerable body of results has been accumulated on solid surfaces of technological or special scientific interest, the assignation of spectral features such as band shifts, or the appearance or disappearance of lines with respect to the gas phase spectra, remains in most cases a very difficult task. DFT predictions of vibrational frequencies can prove immensely helpful in this task, provided the underlying model is realistic and relevant. The above described surface thermodynamics approach at the DFT level has recently met striking successes in that respect. These repeated successes both validate the relevance of this combined approach, and give confidence in its predictive power.

Table 2 displays a comparison, for boehmite, between predicted and experimentally recorded characteristic wavenumbers in the $3500-4000 \mathrm{~cm}^{-1}$ region, corresponding to surface hydroxyl groups observable on an adequately pretreated solid, that is after removal of physisorbed water. The corresponding configurations are displayed in Figure 14. The agreement between theory and experiment is of the order of $10 \mathrm{~cm}^{-1}$ after corrections for anharmonicity [40], a level of accuracy typical for DFT simulations at this level. It is worth emphasizing that the mode predicted at $3712 \mathrm{~cm}^{-1}$, corresponding to the stretching of a hydroxyl bonded to a single octahedral aluminum of the (100) surface $\left(\mu_{1}-\mathrm{Al}_{\mathrm{VI}}\right)$, was later discovered at $3700 \mathrm{~cm}^{-1}$ in the experimental DRIFT spectrum [41]. In view of its weak amplitude, reflecting the minor proportion of (100) faces in precipitated boehmite, the corresponding absorption band had been previously overlooked. Interestingly, this assignment 


\section{TABLE 2}

Ab initio vibrational analysis of boehmite surface hydroxyls. The surface orientations are indexed according to the Miller notation.

\begin{tabular}{c|c|c|c|c|c}
\hline $\begin{array}{c}\text { Type } \\
\text { of } \mathrm{OH}\end{array}$ & Surface & $\begin{array}{c}\text { Relative fraction } \\
(\%)\end{array}$ & $\begin{array}{c}v_{\text {calc. }} \\
\left(\mathrm{cm}^{-1}\right)\end{array}$ & $\begin{array}{c}\mathrm{v}_{\text {exp. }} \\
\left(\mathrm{cm}^{-1}\right)\end{array}$ & $I_{\text {exp. }}$ \\
\hline$\mu_{2}-\mathrm{Al}_{\mathrm{VI}}$ & $(010)$ & 67 & 3676 & 3665 & high \\
$\mu_{2}-\mathrm{Al}_{\mathrm{VI}}$ & $(101)$ & 8 & 3691 & nd & \\
$\mu_{1}-\mathrm{Al}_{\mathrm{VI}}$ & $(100)$ & 12 & 3712 & 3700 & medium \\
$\mu_{1}-\mathrm{Al}_{\mathrm{V}}$ & $(001)$ & 5 & 3741 & nd & \\
$\mu_{1}-\mathrm{Al}_{\mathrm{IV}}$ & $(101)$ & 8 & 3819 & nd & \\
\hline
\end{tabular}

nd: non detected (adapted from [34]).
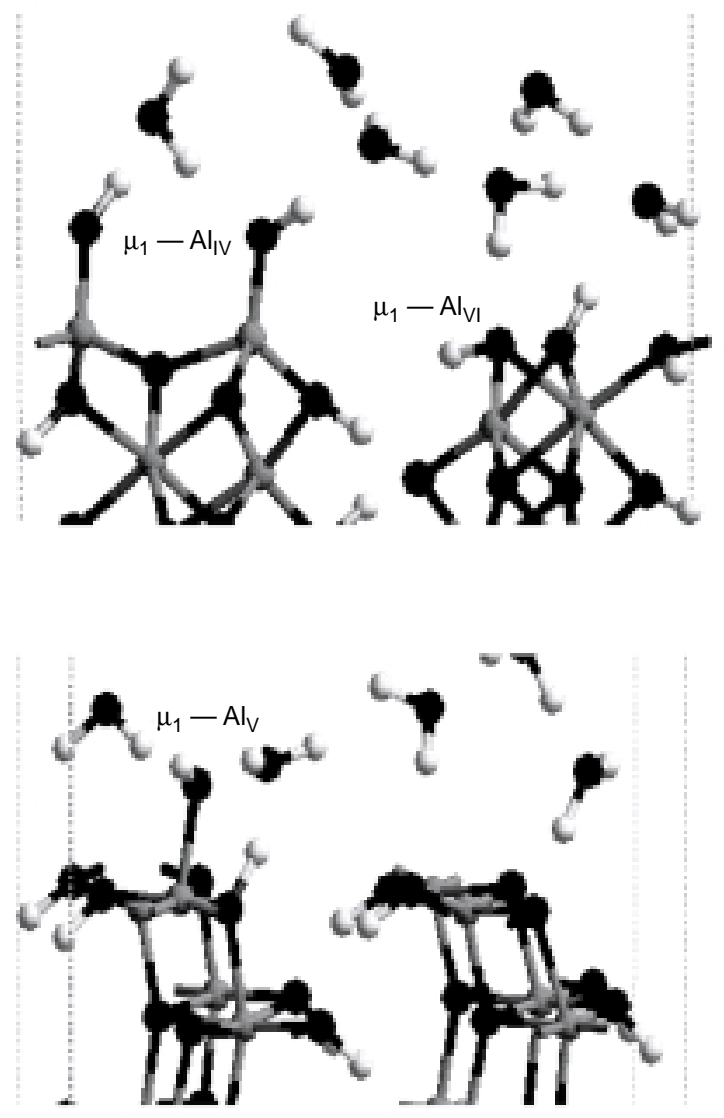

Figure 14

Further samples of equilibrated configurations at waterboehmite interfaces, resulting from $a b$ initio molecular dynamics simulations at $350 \mathrm{~K}$ in the $(\mathrm{N}, \mathrm{V}, \mathrm{T})$ ensemble. (adapted from [34]). Top: (001); bottom: (100).

provides a new method for characterizing the morphology of precipitated boehmite.

\section{ACID-BASE PROPERTIES OF MINERAL SURFACES}

Once relevant models have been determined for fluid/mineral interfaces, DFT can further offer several complementary ways to characterize the acid-base properties of surface species, or sites. It is possible either to simulate calorimetric and spectroscopic experiments involving the adsorption of probe molecules, or to extract relevant local electronic properties from the electronic wavefunction obtained as a solution of the Kohn-Sham Hamiltonian.

Table 3 exemplifies the first approach with results of a study of ammonia $\left(\mathrm{NH}_{3}\right)$ adsorption on boehmite surfaces. Ammonia is a strong Lewis base, which interacts with Brönsted acids, that is proton bearing groups, through its free doublet, tending to form the ammonium ion. The adsorption energies are obtained by substracting the sum of total energies of the isolated substrate and adsorbate from the total energy of the geometry optimized final configuration involving the adsorbate-substrate complex (cf. Equation (10)). These energies correspond approximately to the isosteric heats of adsorption which would have been measured in "clean" experiments. In these experiments low pressure gaseous ammonia would have been adsorbed in the limit of vanishing coverage on oriented perfect surfaces of precipitated boehmite, adequately pre-treated so as to first remove physisorbed water. The accuracy of DFT can be estimated here as being in the range $10-20 \mathrm{~kJ} \cdot \mathrm{mol}^{-1}$. Table 3 shows that, for each orientation, prevailing hydroxyl groups can be classified from the most acidic in the Brönsted sense (most exothermic process) to the least acidic (least exothermic process). The ranking obtained is in no sense intuitive. Table 3 also shows the $\mathrm{N}-\mathrm{H}$ and $\mathrm{H}-\mathrm{O}$ distances in the $\mathrm{N}-\mathrm{-H}-\mathrm{O}$ surface complex corresponding to the minimal energy configuration. As expected, there is a close correlation between the exothermicity of adsorption and the extent of proton transfer from the hydroxyl group towards ammonia (decreasing $\mathrm{N}-\mathrm{H}$ distance and increasing $\mathrm{O}-\mathrm{H}$ distance).

\section{TABLE 3}

$\mathrm{Ab}$ initio characterization of boehmite surface hydroxyls Brönsted acidity through the adsorption enthalpies of ammonia $\left(\mathrm{NH}_{3}\right)$ (adapted from [34])

\begin{tabular}{c|c|c|c|c}
\hline Type of $\mathrm{OH}$ & Surface & $\begin{array}{c}\mathrm{d}\left(\mathrm{H}_{3} \mathbf{N}--\mathbf{H}\right) \\
(\AA)\end{array}$ & $\begin{array}{c}\mathrm{d}\left(\mathrm{H}_{3} \mathrm{~N}-\mathbf{H}-\mathbf{O}\right) \\
(\AA)\end{array}$ & $\begin{array}{c}\Delta \mathrm{H} \\
\left(\mathrm{kJ} \cdot \mathrm{mol}^{-1}\right)\end{array}$ \\
\hline$\mu_{1}-\mathrm{Al}_{\mathrm{V}}$ & $(001)$ & 1.948 & 1.005 & -34.3 \\
$\mu_{1}-\mathrm{Al}_{\mathrm{IV}}$ & $(101)$ & 1.705 & 1.017 & -55.5 \\
$\mu_{2}-\mathrm{Al}_{\mathrm{VI}}$ & $(010)$ & 1.724 & 1.031 & -61.5 \\
$\left(\mathrm{H}_{2} \mathrm{O}\right) \mu_{1}-\mathrm{Al}_{\mathrm{VI}}$ & $(010)$ & 1.598 & 1.053 & -86.1 \\
\hline
\end{tabular}

Another very instructive example is illustrated in Figure 15 which shows adsorption configurations obtained for pyridine on the (100) surface of $\gamma$-alumina in its stable state of hydration under $1 \mathrm{~atm}$ of $\mathrm{H}_{2} \mathrm{O}$ and in the $500-550 \mathrm{~K}$ range [42]. Pyridine can behave, like ammonia, as a probe of Lewis acidity or Brönsted acidity, depending on whether its doublets interact with an electron accepting coordinatively 
unsaturated site, or with a proton donating surface group. The advantage is that the two configurations can in principle be distinguished by a shift towards higher frequencies of the 8 a mode of vibration of the perturbed aromatic ring, with respect to the $1574 \mathrm{~cm}^{-1}$ value for the free molecule in gas phase [43]. We show here the configurations obtained vis-àvis two types of hydroxyls, adjacent on the (100) surface. In configurations a) and $b$ ), pyridine interacts with the $\mathrm{HO}-\mathrm{Al}_{\mathrm{VI}}$ $\left(\mu_{1}\right)$ group, itself initially engaged in a hydrogen bond with the adjacent $\mathrm{Al}_{\mathrm{VI}}-\mathrm{OH}-\mathrm{Al}_{\mathrm{VI}}\left(\mu_{2}\right)$ group: the simulation predicts that it is energetically unfavorable to transfer the proton to form an adsorbed pyridinium. In fact, the most favorable configuration $b$ ) results from a transfer of the second proton from the $\mu_{2}$ to the $\mu_{1} \mathrm{O}$ atom. In fine this results in a pyridine strongly interacting with a water molecule $\mu_{1}$ chemisorbed on an $\mathrm{Al}_{\mathrm{VI}}$, and still weakly hydrogen bonded to a nearby $\mu_{2}$ oxygen. Configurations c) and d) demonstrate that the formation of a pyridinium ion by direct attack on the $\mathrm{Al}_{\mathrm{VI}}-\mathrm{OH}-\mathrm{Al}_{\mathrm{VI}}\left(\mu_{2}\right)$ group is not favoured. An additional conclusion is that the $\mu_{1}$ surface hydroxyl is seen as more acidic in the Brönsted sense than the $\mu_{2}$ one, when probed by pyridine. Overall, these DFT studies brought a very detailed insight, allowing precise assignments of frequencies to well defined configurations. We also confirmed the existence of a good correlation between the $8 \mathrm{a}$ mode red-shift and the strength of adsorption.

Examples of characterization of local and global acid-base properties can be found in [42] again concerning $\gamma$-alumina: it is shown that the Lewis acid character derives from rather localized empty electronic surface states (specific features of the DOS at the bottom of the conduction band) to which $\mathrm{p}$ states from surface aluminum atoms contribute most. The Lewis basic character can be related to delocalized bands, lying below the Fermi level, to which mainly p states from surface oxygens doublets contribute.
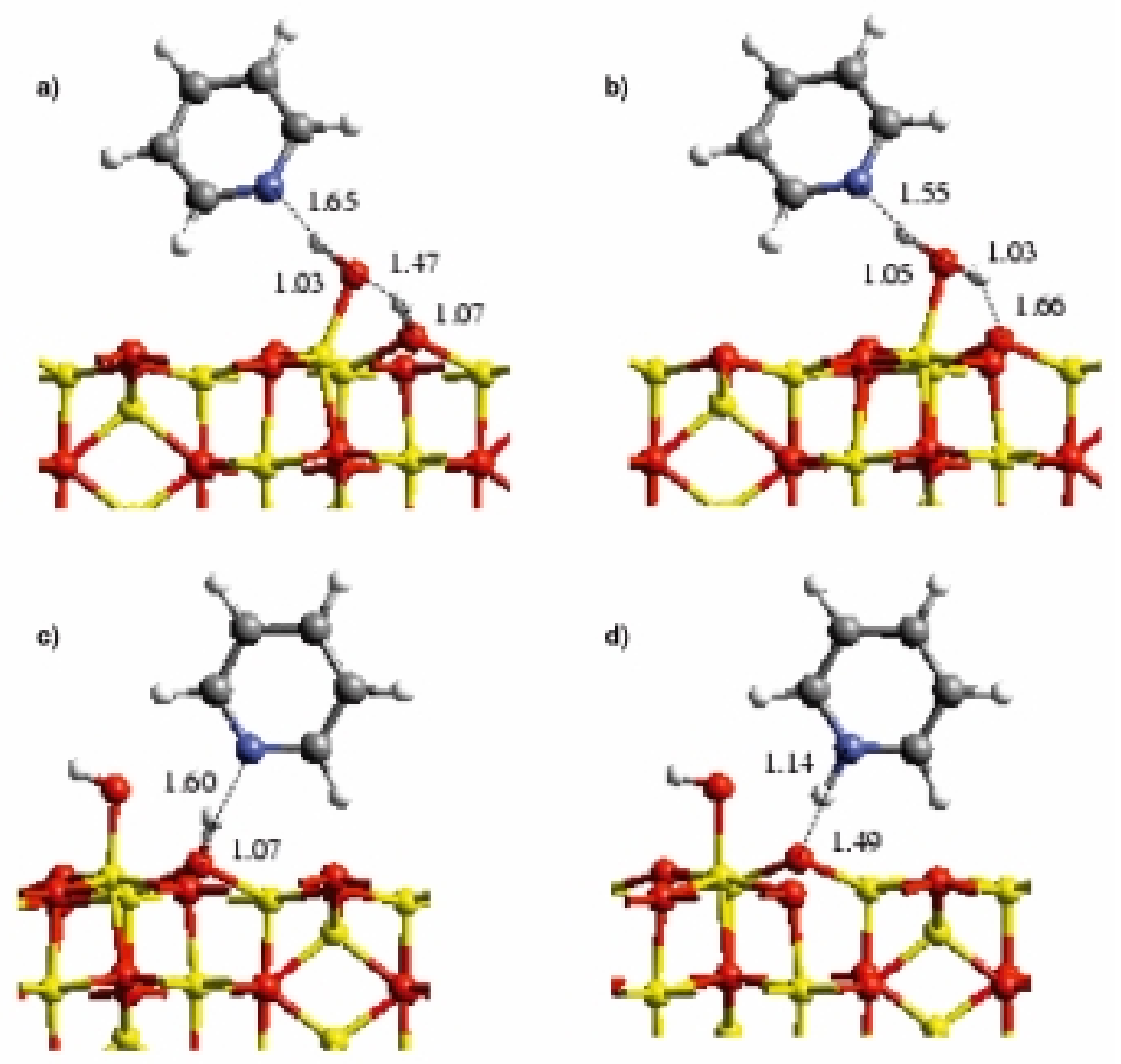

Figure 15

Minimum energy configurations of pyridine in interaction with surface hydroxyls at the (100) surface of $\gamma$ - $\mathrm{Al}_{2} \mathrm{O}_{3}$ (adapted from [42]). The proton transfer to the nitrogen atom of pyridine is never favored. Notice the significance of the simultaneous $\mathrm{H}$-bonding of the $\mu_{1}$-hydroxyl or chemisorbed water, which effectively enhance the Brönsted acidity of the proton interacting with the lone pair of the pyridine nitrogen. a) and b): interactions with $\mu_{1}-\mathrm{Al}_{\mathrm{VI}}, \Delta E=-37$ and $-50 \mathrm{~kJ} \cdot \mathrm{mol}^{-1}$ respectively; c) and d): interactions with $\mu_{2}-\mathrm{Al}_{\mathrm{VI}}, \Delta E=-15$ and $-11 \mathrm{~kJ} \cdot \mathrm{mol}^{-1}$ respectively. 


\section{OUTLOOK: AB INITIO COMPUTATIONAL KINETICS}

We have presented results valid in the limit of thermodynamic equilibrium: however, in geochemical contexts, it is well known that non-equilibrium phenomena are often significant. The overall dynamics of a physicochemical process such as the dissolution or growth of a mineral surface out of equilibrium with a fluid phase, can be described following the principles of statistical physics, provided that all elementary events are known, and that a rate, or probability of occurrence per unit of time, is assigned to each of these events. DFT methods are well suited to compute frequency factors and activation barriers, since not only minima but also other stationary points of the potential energy hypersurfaces can be accurately determined. The localization of saddle points between two local minima requires advanced mathematical techniques such as the socalled "nudged elastic band method" [44]. Although significantly computationally more intensive, these techniques work well and predict almost routinely the associated energy barriers and ratios of partition functions, yielding good estimates of free energy barriers. Once a consistent (and sizable) database of energies, barriers and vibration frequencies has been gathered, it will be possible to go much further in scales of space and time with the implementation of kinetic Monte-Carlo algorithms (kMC) [45], a simulation technique which should in the near future become the natural complement to DFT in the ongoing effort to bridge the gaps between the microscopic description and macroscopic rates of physicochemical processes at surfaces. Successful examples of such simulations have appeared recently in the fields of surface chemistry by CVD [46] and heterogenous catalysis [47], and it is up to the mineral geochemistry community to define the most relevant problems to be tackled by modellers in joint scientific efforts.

\section{CONCLUSION}

We have tried to convince the reader that, as progress in information technologies continues to offer an exponentially increasing computer power, and methodologies mature in accuracy and relevance, ever more complex and challenging speciation problems at fluid/mineral interfaces can be successfully addressed. Theoretical simulations are in many cases able not only to reach experimental accuracy, but moreover, to achieve predictability, that is they prove their ability to guide experiment and to greatly improve the interpretation.

The best results will be obtained when a serious and sustained collaboration is set up between experienced molecular modellers (a professional specialty now well established), or problem solvers, and experimental scientists in the broad sense, or problem definers. Good solutions are actually to the credit of such a team as a whole, in its effort to better define a good problem.

To the extent that synergies can be established, one can expect in a near future significant advances for instance as far as the mecanisms and kinetics of growth and dissolution phenomena of minerals at liquid-solid interfaces are concerned, including the promoting or inhibiting influences of species in electrolytes, the effect of local defects, etc. Research on the physical chemistry of $\mathrm{CO}_{2}$ sequestration should benefit significantly in a near future of such advanced numerical experiments tied to laboratory experiments.

\section{REFERENCES}

1 Chen, J., Kowalewski, I., Toulhoat, H. and Huc, A.Y. (1999) 19th International Meeting of the European Association of Organic Geochemist, Abstracts, Part II, Istanbul, Sep. 6-10, 483-484.

2 Kowalevski, I., Vandenbroucke, M., Taylor, M.J., Faulon, J.L., Behar, F. and Huc, A.Y. (1996) Energy and Fuels, 10, $1,97$.

3 Tunega, D., Gerbazek, M.H. and Lischka, H. (2004) J. Phys. Chem. B, 108, 5930-5936.

4 Stixrude, L. and Peacor, D.R. (2002) Nature, 420, 165.

5 Alfe, D., Gillan, M.J. and Price, G.D. (1999) Nature, 401, 462.

6 Pokrovsky, O.S. and Schott, J. (2002) Surface Chemistry and Dissolution Kinetics of Divalent Metal Carbonates. Environ. Sci. Technol., 36, 426-432.

7 Hohenberg, P. and Kohn, W. (1964) Phys. Rev. B, 136, 864.

8 Kohn, W. and Sham, L.J. (1965) Phys. Rev. A, 140, 1133.

9 Vosko, H., Wilk, L. and Nusair, M. (1980) Can. J. Phys., 58, 1200.

10 Delley, B. (1990) J. Chem. Phys., 92, 508.

11 Troullier, N. and Martins, J.L. (1991) Phys. Rev. B, 43, 1993.

12 Vanderbilt, D. (1990) Phys. Rev. B, 41, 7892.

13 Blöchl, P.E. (1994) Phys. Rev. B, 50, 17953.

14 Kresse, G. and Joubert, D. (1999) Phys. Rev. B, 59, 1758.

15 Perdew, J.P. and Wang, Y. (1992) Phys. Rev. B, 45, 3244.

16 Nosé, S. (1984) Mol. Phys., 52, 255, and Hoover, W.G. (1986) Phys. Rev. A, 34, 2499.

17 Feynman, R.P. (1939) Phys. Rev., 56, 340.

18 Gross, E.K.U., Dobson, J.F. and Petersilka, M. (1996) Topics in Current Chemistry, 181, 81.

19 Benco, L., Demuth, T., Hafner, J., Hutschka, F. and Toulhoat, H. (2001) J. Chem. Phys., 114, 6327.

20 Demuth, T., Rozanska, X., Benco, L., Hafner, J., van Santen, R.A. and Toulhoat, H. (2003) Journal of Catalysis, 214, 68.

21 Toulhoat, H., Raybaud, P. and Benazzi, E. (2004) Journal of Catalysis, 221, 500.

22 Meir, Y., Makarov, D.E. and Kohn, W. (1998) Phys. Rev. Lett., 80, 4153.

23 Kresse, G. and Furthmüller, J. (1996) Phys. Rev. B, 54, 11961, and Kresse, G. and Furthmüller, J. (1996) Computational Materials Science, 6, 15.

24 Payne, M.C. et al. (1992) Rev Mod. Phys., 64, 1045.

25 http://www.gaussian.com 
26 http://www.schrodinger.com/

27 The MedeA Suite of Modules is Marketed by Materials Design SARL, Le Mans, France, http://www.materialsdesign.com

28 Raybaud, P., Kresse, G., Hafner, J. and Toulhoat, H. (1997) J. Phys.: Condens. Matter, 9, 11, 85.

Raybaud, P., Hafner, J., Kresse, G. and Toulhoat, H. (1997) J. Phys.: Condens. Matter, 9, 11, 107.

29 Digne, M., Sautet, P., Raybaud, P., Toulhoat, H. and Artacho, E. (2002) J. Phys. Chem. B, 106, 5155.

30 Krokidis, X., Raybaud, P., Gobichon, A.E., Rebours, B., Euzen, P. and Toulhoat, H. (2001) J. Phys. Chem. B, 105, 5121.

31 Turchi, P. (1994) Electronic Theory of Alloy Phase Stability. In: Intermetallic Compounds, Westbrook, J.H. and Fleischer, R.L. (eds), John Wiley and Sons, New York.

32 Digne, M. (2003) Thesis, École normale supérieure de Lyon.

33 Ge, Q., Kose, R. and King, D.A. (2000) Advances in Catalysis, 45, 207.

34 Raybaud, P., Digne, M., Iftimie, R., Wellens, W., Euzen, P. and Toulhoat, H. (2001) Journal of Catalysis, 201, 236.

35 Wulff, G.Z. (1901) Z. Kristallogr., 34, 449.

36 Froidefond, C. (2002) Thesis, Université Pierre et Marie Curie, Paris.

Jolivet, J.P., Froidefond, C., Pottier, A., Chanéac, C., Cassaignon, S., Tronc, E. and Euzen, P. (2004) Journal of Materials Chemistry, 14, 3281.
37 Arrouvel, C., Digne, M., Breysse, M., Toulhoat, H. and Raybaud, P. (2004) Journal of Catalysis, 222, 152.

38 Arrouvel, C., Breysse, M., Toulhoat, H. and Raybaud, P. (2004) Journal of Catalysis, 226, 260.

39 Coulier, L., van Veen, J.A.R. and Niemantsverdriedt, J.W. (2002) Catal. Lett., 79, 149.

40 Ugliengo, P. ANHARM - A Program to Solve Numerically the Monodimensional Nuclear Schrödinger Equation, Unpublished.

41 Armaroli, T., Minoux, D., Gautier, S. and Euzen, P. (2003) Applied Catalysis, 251, 241.

Minoux, DS. (2002) Thesis, Université Pierre et Marie Curie, Paris.

42 Digne, M., Sautet, P., Raybaud, P., Euzen, P. and Toulhoat, H. (2004) Journal of Catalysis, 226, 54.

43 Morterra, C. and Magnacca, G. (1996) Catal. Today, 27, 497.

44 Mills, G., Jonnson, H. and Scheuter, G.K. (1995) Surf. Sci., 324, 305.

45 Bortz, A.B., Kalos, M.H. and Lebowitz, J.L. (1975) J. Comp. Phys., 17, 10.

46 Kratzer, P., Penev, E. and Scheffler, M. (2003) Applied Surface Science, 216, 436.

47 Hansen, E.W. and Neurock, M. (1999) Chem. Eng. Sci., 54, 3411.

Final manuscript received in January 2005 